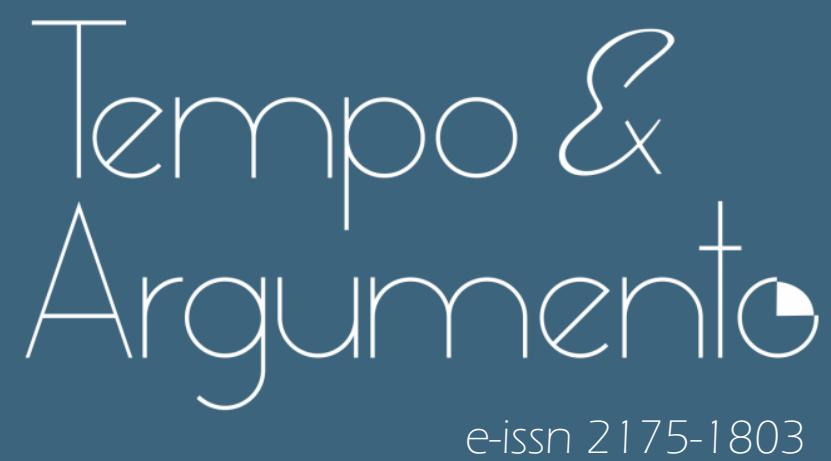

\title{
Mujeres pensionadas por la Junta para la Ampliación de Estudios en Pedagogía (1907-1940). El caso de Castilla y León
}

\footnotetext{
Miriam Sonlleva Velasco

Doctora en Educación por la Universidad de Valladolid.

Profesora del Departamento de Pedagogía de la Universidad de Valladolid.

Valladolid - ESPAÑA

dialnet.unirioja.es/servlet/autor?codigo=3737730

miriam.sonlleva@uva.es

(iD) orcid.org/0000-0001-6268-8670
}

is Carlos Sanz Simón

Doctor en Educación y contratado postdoctoral en el Departamento de Estudios

Educativos de la Universidad Complutense de Madrid.

Madrid - ESPAÑA

dialnet.unirioja.es/servlet/autor?codigo $=4015244$

csa02@ucm.es

(iD) orcid.org/0000-0002-5786-4024

Para citar este articulo (ABNT):

SONLLEVA VELASCO, Miriam; SANZ SIMÓN, Carlos. Mujeres pensionadas por la Junta para la Ampliación de Estudios en Pedagogía (1907-1940). El caso de Castill. y León. Tempo e Argumento, Florianópolis, v. 13, n. 32, e0206, jan./abr. 2021.

http://dx.doi.org/10.5965/2175180313322021e0206 


\title{
Mujeres pensionadas por la Junta para la Ampliación de Estudios en Pedagogía (1907-1940). El caso de Castilla y León ${ }^{1}$
}

\begin{abstract}
Resumen
La Junta para la Ampliación de Estudios (JAE) fue una institución creada en 1907 con la finalidad de abrir las fronteras del conocimiento en España. A través de su sistema de pensiones, profesionales de múltiples disciplinas viajaron al extranjero para conocer las principales teorías y corrientes de sus campos de estudio. El presente trabajo se propone profundizar en el conocimiento de las mujeres del ámbito de la pedagogía que fueron becadas por la Junta desde Castilla y León entre 1907 y 1940 y analizar la incidencia de los viajes realizados en sus trayectorias tras la rebelión producida en España en 1936. El estudio se vertebra desde el método histórico-educativo y se sirve de los expedientes de estas profesionales disponibles en el archivo de la JAE (Madrid), de los expedientes de depuración albergados en el Archivo General de Administración, así como de los expedientes profesionales recuperados en archivos provinciales, documentos triangulados con otras fuentes legales. Para su análisis hemos clasificado, primero, a las pensionadas en función de su cargo y, posteriormente, en función de si fueron penalizadas en los procesos de depuración iniciados durante la Guerra Civil o no. Las conclusiones nos permiten afirmar que las profesionales que se comprometieron con el movimiento renovador de comienzos del siglo XX -y especialmente con el proyecto educativo republicano - sufrieron las consecuencias más duras del proceso depurador.
\end{abstract}

Palabras clave: Mujer. Junta para la Ampliación de Estudios. Castilla y León. Internacionalización.

\section{Women granted a pension by the Junta para la Ampliación de Estudios in Pedagogy (1907-1940). The case of Castile and Leon}

\begin{abstract}
The "Junta para la Ampliación de Estudios" (JAE) was an institution created in 1907 with the aim of opening the frontiers of knowledge in Spain. Through its pension system, professionals from many disciplines traveled abroad to learn about the main theories and currents in their fields of study. The present work aims to deepen the knowledge of the women in the pedagogical field who were granted scholarships by the Junta from Castile and Leon between 1907 and 1940 and to analyze the incidence of the trips made in their trajectories after the rebellion produced in Spain in 1936. The study is based on the historical-educational method and makes use of the files of these professionals available in the JAE archive (Madrid), the purification files housed in the General Administration Archive, as well as the professional files recovered in provincial archives, documents triangulated with other legal sources. In order to analyse them, we have first classified the pensioners according to their posts and, later, according to whether they were penalised in the purging processes initiated during the Civil War or not. The conclusions reveal that the professionals who were committed to the renovation movement at the beginning of the 20th century -and especially to the republican educational projectsuffered the harshest consequences of the purge process.
\end{abstract}

Keywords: Woman. Junta para la Ampliación de Estudios. Castile and Leon. Internationalization.

\footnotetext{
Este trabajo se enmarca en las líneas de estudio derivadas del proyecto i+D titulado Totalitarismos y exilio interior de las educadoras en España (1923-1975): Silencios, resistencias y resignificaciones, concedido por el Ministerio de Ciencia e Innovación del Gobierno de España para el periodo 2020-2023 (No. Ref. PID2019-105817GB-I00 / AEl / 10.13039/501100011033). Asimismo, esta investigación ha sido posible también gracias a un contrato de personal investigador en formación, cofinanciado por la Universidad Complutense de Madrid y el Banco Santander (Convocatoria CT17/17-CT18/17).
} 


\section{Introducción}

La política de pensiones que promovió la Junta para la Ampliación de Estudios e Investigaciones Científicas en el primer tercio del siglo XX fue clave para que distintos profesionales españoles viajaran fuera de España, mejoraran su cultura y formación y conocieran diferentes experiencias renovadoras.

En la actualidad, son varios los estudios que han tratado de profundizar en la prolífica línea de investigación abierta por Teresa Marín Eced a finales del siglo XX. Sin embargo, trabajos como el de Comas (2007) reflejan la necesidad de avanzar en este campo de conocimiento desde una perspectiva local. Descendiendo al análisis de los estudios publicados, podemos apreciar cómo la mayoría de las investigaciones adolecen de tres problemas: a) exponen datos exclusivamente cuantitativos y centrados en las pensiones -no en los pensionados-; b) no prestan atención a la biografía de quienes fueron destinatarios de dichas pensiones; y c) no toman en cuenta, por lo general, la variable género como eje trasversal de los estudios realizados.

Entre las investigaciones que sí consideran esta variable de género, se presentan trabajos basados en los países de destino (LEMUS, 2019; MENDOZA, 2016), en perfiles profesionales determinados (ARAQUE, 2014; GARCÍA, 2007; RABAZAS; RAMOS, 2007; ROBLES, 2007), en disciplinas educativas (DELGADO; LÓPEZ, 2007; NÚÑEZ; REBOLLO, 2007), en estudios de caso (HERNÁNDEZ, 2007), en la represión ejercida por el franquismo (MARÍN, 2010), en aportaciones pedagógicas (COLMENAR, 2007) o en su vinculación con instituciones específicas, como el caso de la Residencia de Señoritas (MAGALLÓN, 2007a). Sin embargo, se advierte una carencia de estudios que desciendan hacia una perspectiva regional en esta línea de investigación. Este tipo de investigaciones son clave para incluir a la mujer como sujeto histórico e historiar un pasado con nombres propios.

Estas premisas de partida fueron las que nos llevaron a realizar la presente investigación, cuyo objetivo principal es profundizar en el conocimiento de las mujeres que fueron becadas por la Junta para la Ampliación de Estudios en 
Mujeres pensionadas por la Junta para la Ampliación de Estudios en Pedagogía (1907-1940).

El caso de Castilla y León

Miriam Sonlleva Velasco, Carlos Sanz Simón

Castilla y León² entre 1907 y 1940. Desde este objetivo general nos planteamos dos específicos: a) conocer los destinos y las líneas de trabajo de las pensionadas, de acuerdo con su categoría profesional; y b) analizar la incidencia de los viajes realizados por las profesionales y su formación renovadora tras la rebelión producida en España a partir de 1936.

\section{La mujer y su búsqueda del conocimiento internacional}

La Junta para la Ampliación de Estudios e Investigaciones Científicas JAE- fue una institución creada en España en 1907 (MINISTERIO DE INSTRUCCIÓN PÚBLICA Y BELLAS ARTES, 1907a). Presidida por Santiago Ramón y Cajal, hasta su muerte en 1934, y más tarde por Ignacio Bolívar, se convirtió en una poderosa agencia de modernización pedagógica en el desolador panorama educativo que ofrecía el contexto español a comienzos del siglo XX. Surgida desde los planteamientos de la Institución Libre de Enseñanza, su fin fue el impulso de la ciencia y la mejora de la formación del profesorado. Para la primera línea de actuación, se incorporaron los métodos y técnicas de investigación más actuales; para la segunda, se trasplantaron las teorías y contribuciones pedagógicas más exitosas del momento. Con estos propósitos se enviaron a titulados españoles a los focos científicos y pedagógicos de mayor renombre con el fin de estudiar los nuevos saberes y aprender los nuevos métodos de investigación y enseñanza. Su único compromiso a la vuelta era la difusión de sus aprendizajes (RUIZ BERRIO, 2000). Precisamente, sus conocimientos fueron el revulsivo para transformar el

\footnotetext{
${ }^{2}$ Queremos destacar que este trabajo surge de la necesidad de contemplar la perspectiva local y toma como punto de partida el análisis previo realizado, centrado en el mismo contexto en la dictadura de Miguel Primo de Rivera, entre 1923 y 1930 (SANZ; SONLLEVA, 2020). Asimismo, nos gustaría mencionar que la Comunidad Autónoma de Castilla y León nace de la unión de los territorios históricos que componían las antiguas coronas de León y Castilla. Tras la dictadura franquista y los avances en la descentralización del periodo de la Transición democrática, el 25 de febrero de 1983 las Cortes aprobaban la Ley Orgánica 5/1983 -sancionada por el Rey Juan Carlos I el 1 de marzo del mismo año- por la que Segovia se unía a las ocho provincias castellanoleonesas (Burgos, Soria, Ávila, Valladolid, Palencia, León, Zamora y Salamanca). El 8 de mayo de 1983 tuvieron lugar las primeras elecciones autonómicas. A pesar de que la Comunidad de Castilla y León surge tiempo después de la desaparición de la JAE, desde 1883 algunas de sus provincias (Ávila, Burgos, Segovia, Soria, Palencia y Valladolid- junto con Logroño y Santander-) formaban parte del reino de Castilla la Vieja, mientras Salamanca, Palencia y León lo eran del reino de León. La vinculación entre ambos reinos por su proximidad territorial se constata a lo largo del siglo XIX y el siglo XX. Este criterio de proximidad ha sido el que hemos tenido en cuenta para trazar el estudio a nivel regional.
} 
obsoleto escenario científico y educativo de un país retrasado respecto al contexto europeo.

En el reglamento de la Junta, al comienzo de su creación, se especificaba que se realizaría "todos los años una convocatoria para la concesión de pensiones en el extranjero al Profesorado de los establecimientos de enseñanza dependientes del Ministerio de Instrucción Pública y Bellas Artes" (MINISTERIO DE INSTRUCCIÓN PÚBLICA Y BELLAS ARTES, 1907b). Sin embargo, las mujeres no tuvieron las mismas oportunidades que los hombres. Hasta la primera década del siglo XX el colectivo femenino no podía matricularse en las universidades sin previa consulta a la autoridad y su excepcional incorporación a las aulas no significó en muchos casos su ejercicio profesional (BALLARÍN, 1989). De esta forma, se produjo un desequilibrio de partida respecto al número de profesionales formados en aquel periodo.

La JAE mantuvo una línea aperturista hacia la incorporación de las mujeres en la vida pública, como consecuencia de la importante influencia y vinculación que esta institución tuvo con la Institución Libre de Enseñanza (ALCALÁ; MAGALLÓN, 2008). Este aperturismo se articuló alrededor de varias instituciones. Raquel Vázquez Ramil ha resumido sus contribuciones en torno a la vertiente científica y la pedagógica, aunque por la propia naturaleza de este estudio nos centraremos en esta última. Como punto de partida se debe considerar que los resultados obtenidos desde una perspectiva educativa fueron menos apreciables. No obstante, se resumen a través de dos instituciones creadas a su albor: la Residencia de Estudiantes y el Instituto Escuela. La primera de ellas, nacida en 1910, buscó ofrecer un espacio donde alojar al alumnado en un entorno refinado y selecto, completando la enseñanza universitaria que este recibía y sirviendo así como un centro de difusión cultural en muy variadas áreas. La segunda, fundada en 1918, surgió de la necesidad de explorar un nuevo modelo educativo más completo y apropiado para la época, y que tuviera un grupo sólido en su profesorado que pudiera divulgar el proyecto (VÁZQUEZ, 2012).

No obstante, el papel de la mujer sería visible en otra institución, cuya historia no puede explicarse sin su contextualización en las aquí mencionadas: la Residencia de Señoritas. Creada en 1915 y dirigida por María de Maeztu -la que 
fuera su directora y vocal en la propia JAE- "desempeñó un papel de primer orden en la incorporación de las mujeres a la carrera científica y su integración a los centros de investigación y laboratorios de la JAE" (OTERO, 2018, p. 296). La principal aportación de esta institución se resume en el "sólido apoyo que prestó viabilidad práctica a los proyectos de formación superior de las que no tenían posibilidad de estudiar en su lugar de origen" (ALCALÁ; MAGALLÓN, 2008, p. 145). Sin embargo, esta institución difirió en cuanto a sus objetivos con su homónima masculina, optando "por una vía más práctica, directa y eficaz a corto plazo que la ensayada con sus compañeros, tal vez más diletante ésta y sin duda más brillante" (VÁZQUEZ, 2012).

Como fruto de la estrecha colaboración entre la JAE y la Residencia de Señoritas hay que destacar la fuerte vinculación que se estableció con el International Institute for Girls in Spain (IIGS), un centro creado por una fundación de similar denominación con sede en Boston. Esta afinidad se debió a la similitud de ideas acerca de la educación de ambas instituciones (MAGALLÓN, 2007a). La colaboración reflejaba el vigor del proyecto educativo que emanaba de la propia Junta y de la Institución Libre de Enseñanza, y la iniciativa para que la mujer formara parte de él. Además, también se firmaría un convenio de colaboración en 1920 con la Association of Collegiate Alumnae, cuya cooperación tuvo como finalidad "la concesión de becas universitarias a españolas en Estados Unidos" (OTERO, 2018, p. 296).

Descendiendo a las propias ayudas concedidas por la JAE, se puede considerar que cumplieron un papel fundamental en la incorporación de la mujer, algo especialmente palpable en el ámbito científico (ALCALÁ; MAGALLÓN, 2008). No obstante, si acudimos a los datos totales se aprecia que, aunque se presentó un paulatino crecimiento en el número de pensiones recibidas por mujeres desde la creación de la Junta, estas fueron siempre claramente inferiores a las recibidas por los hombres, representando cifras ínfimas -sobre todo al inicio- respecto al total. Entre 1907 y 1934 la Junta recibió 8149 instancias de pensión y concedió 1594. El número total de mujeres pensionadas fue de 156 (GÓMEZ, 1976, p.46).

Tomando los datos proporcionados por Marín (1990, p. 88) y referidos exclusivamente al ámbito educativo, observamos que en el periodo comprendido 
entre 1908 y 1919, se concedieron tan solo 27 ayudas a mujeres de las 645 asignadas en total. Este dato representaba el 4\% de las becas concedidas, cifra que aumentó en los años veinte. Entre 1920 y 1929, las mujeres fueron beneficiarias de 41 ayudas de un total de 539. El ascenso al 8\%, aumentaba el número de pensiones concedidas a mujeres durante esta década -en términos proporcionales-. Finalmente, durante los últimos años de andadura de la JAE, se concedieron 53 ayudas a mujeres de un total de 410, lo que supuso un 13\% del total. Este último dato representa, como señala Magallón (2007b), un porcentaje ligeramente superior al de mujeres matriculadas en las aulas universitarias.

En las ayudas concedidas a mujeres en materia educativa, hay que destacar el papel que tuvo la enseñanza de las Ciencias. Tanto Magallón (2007b) como Otero (2018) coinciden en señalar la importancia de estas ayudas. En esta línea, fueron becadas mujeres de la talla de Martina Casiano Mayor, Dolores Cebrián Fernández Villegas, Luisa Cruces Matesanz o Rosa Sensat i Vila, con una trayectoria destacable (MAGALLÓN, 2007b).

En definitiva, la Junta contempló en sus planteamientos iniciales la incorporación de la mujer en la importación del conocimiento internacional. El número de ayudas fue claramente inferior al concedido a los varones, si bien su crecimiento progresivo supuso un avance para la formación de la mujer.

\section{Apuntes metodológicos}

La presente investigación se enmarca en el paradigma cualitativo y se asienta en el método de investigación histórico-educativo (RUIZ, 1976). Nos adentramos en las etapas del método para dar a conocer los aspectos metodológicos de la presente investigación.

Avanzando en el planteamiento de esta, el estudio se centra en recuperar la trayectoria biográfica de las mujeres de la actual comunidad autónoma de Castilla y León, que fueron pensionadas por la JAE en el primer tercio del siglo XX desde el ámbito de la Pedagogía, profundizar en los destinos y las líneas de trabajo de estas profesionales en sus viajes en el extranjero y conocer la incidencia de su relación con la Junta en su trayectoria profesional tras la Guerra 
Civil. Si bien existen muchas investigaciones en nuestros días que abordan a nivel cuantitativo el sistema de las pensiones en este periodo, no son abundantes las que profundizan sobre las biografías de los pensionados y su carácter profesional. Estudios como el de Comas (2007), invitan además a revisar esta temática de estudio desde una perspectiva local.

Siguiendo estas directrices, desde la heurística, la investigación ha sido construida con tres fuentes primarias fundamentales: a) Los expedientes de cada una de las profesionales que componen la muestra del estudio, albergados en el archivo de la Junta para la Ampliación de Estudios e Investigaciones Científicas de la Residencia de Estudiantes de Madrid (España). Dichos expedientes nos han permitido analizar el número de ayudas recibidas por cada una de ellas, el perfil de las solicitantes, la descripción de las actividades realizadas a lo largo de la estancia y los trabajos elaborados; b) Los expedientes de depuración de las profesionales vinculadas al ámbito educativo, que se encuentran albergados en el Archivo General de la Administración de Alcalá de Henares (España). La documentación contenida en cada expediente ha sido clave para poder descubrir la incidencia que tuvo el aprendizaje europeo en sus trayectorias profesionales y sus repercusiones en el proceso depurador; y c) Los expedientes profesionales de muchas de estas mujeres (principalmente aquellas dedicadas a la docencia), rescatados del Centro Documental de la Memoria Histórica de Salamanca (España); del Archivo Histórico Provincial de Valladolid (España); y del Archivo Histórico Provincial y el Archivo Territorial de Segovia (España). Estos expedientes nos han permitido conocer su trayectoria antes de solicitar las pensiones, saber dónde habían cursado sus estudios, descubrir cuáles fueron sus primeros destinos profesionales y, en definitiva, analizar la experiencia profesional previa de cada una de ellas.

La muestra del estudio se compone de un total de 35 mujeres que fueron pensionadas desde la actual región de Castilla y León a diferentes países europeos y americanos entre 1907 y 1940. Una primera fase del estudio consistió en organizar toda la información recuperada de cada una de las mujeres protagonistas de la investigación, bajo expedientes individuales. Tras una lectura pormenorizada del material disponible, se procedió a su análisis y triangulación 
con fuentes secundarias y complementarias (disposiciones oficiales, publicaciones secundarias y documentación biográfica rescatada de hemerotecas).

Después de realizar una crítica interna y externa del material, procedimos a organizar la biografía de cada protagonista de la muestra dividiéndola en dos marcos temporales: antes de 1936 y después de 1936. Tras la división, buscamos conexiones entre las profesionales, poniendo en discusión cada trayectoria individual con la del grupo profesional al que pertenecían y también con la del conjunto que conforma la muestra. Estas secuencias de análisis han resultado fundamentales para tener una perspectiva individual de cada protagonista y a la vez tener una panorámica de conjunto.

Para la exposición de resultados hemos optado por presentar la información bajo dos epígrafes: 1) Destinos y líneas de trabajo de las pensionadas por grupos profesionales; y 2) Trayectoria de las pensionadas tras la Guerra Civil. En cada uno de estos epígrafes dividimos la información analizada de acuerdo con las directrices seguidas en nuestro propio análisis interno y hemos optado por un estilo argumental que destaque la perspectiva individual, con el objetivo de presentar algunos rasgos biográficos de estas mujeres y no caer en datos de conjunto que invisibilicen sus trayectorias personales.

\section{Las mujeres de Castilla y León, vinculadas al ámbito pedagógico y su afán por el conocimiento}

No fueron muchas las mujeres de la región castellanoleonesa que solicitaron pensión a la JAE entre 1907 y 1940. Desde el ámbito pedagógico, treinta cinco profesionales pudieron disfrutar del aprendizaje fuera de España y mejorar su formación. Se trataba de un grupo de mujeres comprometidas profesionalmente y con ansias de renovar la realidad que vivía el país en el primer tercio del siglo XX. Así lo muestran sus líneas de trabajo y lo reflejan sus memorias. 


\subsection{Destinos y líneas de trabajo de las pensionadas por grupos profesionales}

Los destinos elegidos por las distintas profesionales se enmarcan mayoritariamente en Europa. Sin embargo, sus intereses difieren en función de la categoría profesional, como veremos a continuación.

\section{A) Inspectoras}

Siete inspectoras de la actual comunidad de Castilla y León fueron becadas por la Junta para la Ampliación de estudios entre 1907 y 1940. Sus nombres, como se aprecia en la tabla 1, resultan conocidos a nivel nacional por la relevancia que estas mujeres tuvieron en la educación española de la primera mitad del siglo XX.

Tabla 1 - Inspectoras pensionadas por la JAE en Castilla y León (1907-1940)

\begin{tabular}{rllll}
\hline \multicolumn{1}{c}{ Año/s } & \multicolumn{1}{c}{ Apellidos y nombre } & Origen & Destino & Materia \\
\hline $1922 /$ & Alfaya López, María de la & Segovia & FR, B & Educación \\
1935 & Paz & & & \\
$1922-1924$ & Cadenas Campo, Cándida & Zamora & EEUU & Educación \\
1922 & Díez y Díez, Adelaida & Valladolid & FR, B, SU & Educación \\
$1931-1933$ & Morros Sardá, Julia & León & FR, B, SU & Educación \\
1934 & Ballesteros y Usano, María & Segovia & FR, B, SU & Educación \\
& de los Dolores & & & \\
1934 & Gil y Febrel, María Cruz & Soria & FR, B, SU, I & Educación \\
1935 & Antelo Rodríguez, María de & Zamora & SU & Educación \\
& los Ángeles & & & \\
\hline
\end{tabular}

Fuente: Elaboración propia, 2020

Adelaida Díez y María de la Paz Alfaya obtuvieron sus títulos de maestras elementales en 1906 y 1909 respectivamente. Fueron mujeres activas en su profesión desde el comienzo de su carrera. La primera cursó estudios de Maestra Normal en la sección de Ciencias y realizó cursos sobre Ciencias en la Escuela Central de Artes e Industrias y sobre Mineralogía en la JAE (FLECHA, 2018, p. 206). Ingresó en el año 1911 en Valladolid como socia de la Real Sociedad Española de

\footnotetext{
En esta tabla solo aparecen aquellas inspectoras cuya concesión de la pensión aparece publicada en disposiciones oficiales. Han quedado excluidas otras como Victoria Adrado e Iglesias, inspectora salmantina que solicitó pensión en 1914 para visitar escuelas de Francia, Bélgica y Suiza, pero la resolución de su solicitud no aparece publicada.
} 
Historia Natural. Adelaida Díez es una de las diez primeras inspectoras españolas que fueron nombradas en 1913 (MINISTERIO DE INSTRUCCIÓN PÚBLICA Y BELLAS ARTES, 1913).

La segunda, María de la Paz Alfaya, después de su formación inicial, ingresó como alumna oficial en la Escuela de Estudios Superiores del Magisterio a comienzos de otoño de 1914. Fue nombrada Profesora Numeraria de Gramática y Literatura Castellana en la Escuela Normal de Maestras de Lugo en 1919, pero no llegó a tomar posesión del cargo, pues accedió el 19 de julio de 1920 al puesto de Inspectora de Primera Enseñanza de Segovia, del que tomó posesión una semana después (MORENO, 2019, p. 30).

Desde sus comienzos, ambas profesionales mostraron un claro interés por perfeccionar su formación y acercarse al conocimiento reformista europeo. Apenas pasados unos años de tomar posesión como inspectoras de primera enseñanza, solicitaron a la JAE en 1922 una pensión para viajar al extranjero. Formaron parte del primero de los grupos de carácter pedagógico de Inspectores de Primera Enseñanza aprobado por la Real Orden 21 de abril de 1922, cuyo fin era visitar durante dos meses los establecimientos escolares de Francia y Bélgica y realizar prácticas docentes y de inspección. Este viaje de estudios estaba dirigido por el también inspector Eladio García Martínez y formaron parte del grupo otros siete profesionales de la inspección.

Los pensionados designados, además de redactar el diario de la excursión, debían presentar un trabajo individual acerca de una cuestión concreta de metodología u organización escolar. A pesar de que en los expedientes de ambas inspectoras no hay constancia de dicho trabajo, sí lo hay, en cambio, en el expediente del director del viaje, Eladio García, titulado "Algunas notas escolares de Francia, Bélgica y Suiza”. Este ensayo nos permite ver que el grupo visitó escuelas maternales, elementales, superiores y Normales. De las primeras llama la atención del colectivo los métodos frobelianos, el juego, la gimnasia sueca y de Dalcroce, así como los fundamentos de la lectura y el cálculo. De las segundas, su organización, didáctica e innovación a nivel metodológico. En cuanto a las Normales, los pensionados resaltan el valor de la formación superior para 
despertar las conciencias y dar ideales fuertes para formar a un Magisterio que valiera más por lo que hiciera que por lo que supiera (GARCíA, 1924).

El caso de Cándida Cadenas Campos, coetánea de estas dos inspectoras, resulta peculiar. Se formó profesionalmente en la Escuela de Estudios Superiores del Magisterio en la década de 1910. Durante su formación se alojaba en la Residencia de Señoritas de Madrid. Ingresó, como María de la Paz Alfaya, en 1920, en el cuerpo de la inspección. Su cercanía durante esta etapa formativa al institucionismo, le llevó a solicitar en 1922 una pensión para realizar estudios en el extranjero. Fue becada a Estados Unidos, a propuesta del Comité de Becas para Mujeres Españolas, durante los cursos 1922-1924, según Reales Órdenes de 9 de junio de 1922 y 1 de julio de 1923. La inspectora, a diferencia de todas sus compañeras, tenía especial interés por el conocimiento del deporte y su incorporación a la enseñanza femenina. Permaneció dos cursos en Ste. Catherine College, de San Pablo (Minnesota), siguiendo cursos de Educación Física y visitando escuelas públicas en Minneapolis. Los resultados de su trabajo fueron bien recibidos por el gobierno estadounidense, que le concedió una beca en Chicago y después una prórroga para impartir clases de español en la Universidad de Madison, en Wisconsin. En este segundo curso, continuó formándose en Educación Física y visitando algunas escuelas para conocer la organización escolar. En el verano se incorporó a un campamento de "Girls Scouts" en Chicago y tomó parte en las prácticas, sufriendo los exámenes finales(JUNTA PARA LA AMPLIACIÓN DE ESTUDIOS E INVESTIGACIONES CIENTÍFICAS, 1935a).

En su expediente puede comprobarse el afán por aprender que mostró Cadenas durante su estancia en el extranjero. A pesar de haber aprendido inglés en España, le resultaba difícil tener trato con personas estadounidenses, pues como escribía en una carta la propia Cándida a José Castillejo, "el carácter de estas gentes es tan frío, que me cuesta mucho acostumbrarme y me siento muy sola y aislada entre tanta gente" (JUNTA PARA LA AMPLIACIÓN DE ESTUDIOS E INVESTIGACIONES CIENTÍFICAS, 1935a, p. 53). En la memoria que presentó al finalizar su estancia, titulada "Recuerdo sobre mis trabajos de Educación Física", se percibe su preocupación por la formación femenina, hecho que marcará su 
trayectoria profesional y le llevará a convertirse en un referente de la Educación Física femenina en España.

Julia Morros, María de Los Dolores Ballesteros, María Cruz Gil y María de los Ángeles Antelo, compartieron destino con las inspectoras Alfaya y Díez. Sus estancias en el contexto francés, belga y suizo se enmarcan en el periodo de la II República, a pesar de que algunas de ellas ya habían solicitado — sin éxito - ser pensionadas en convocatorias previas.

Julia Morros perteneció a la promoción 1922-1926 de la Escuela Superior del Magisterio. Como sus compañeras, se interesó pronto por la renovación europea. Tenía una amplia formación docente y científica, pues se licenció en Ciencias Naturales y fue profesora de Ciencias en el Instituto-Escuela. Pidió varias becas antes de ser pensionada, pero no fue hasta 1931 cuando recibió confirmación positiva. Había escrito por entonces ensayos de gran relevancia como el titulado "Evolución del juicio en los niños (normales y sordomudos) durante el periodo escolar. Un ensayo de Psicología Experimental” o "Valores y relaciones cefálicas de las niñas madrileñas", trabajos que fueron bien valorados para la concesión de su pensión. En calidad de pensionada, la inspectora pasó diez meses -entre 1931 y 1933 - en Francia, Bélgica y Suiza, realizando estudios de Psicología Experimental, Antropología, e interesándose por la cuestión metodológica.

En el primero de estos países, además de realizar visitas a los principales talleres de aprendizaje de París, asistió a los cursos de Paidología del Doctor Wallon; Psicología Experimental del Doctor Pieron; Fisiología del Doctor Laugier y realizó prácticas en el Laboratorio de La Sorbona y en la Escuela de Artes y Oficios. Además, participó en Cursillos de Orientación Profesional, asistió al curso de la Escuela de Antropología y después realizó trabajos prácticos. En el país belga asistió como alumna libre a diferentes clases de la Facultad de Pedagogía, realizó prácticas de antropología en la Clínica de Vermeylen y asistió al curso especial sobre el método Decroly. Además, visitó las organizaciones escolares características de Bélgica (Laboratorio Psico-Pedagógico de Angleur, en Lieja; y la Granja-Escuela de Waterloo). En Suiza se interesó por las clases del Instituto 
Rousseau, impartidas por Claparède, Bovet y Piaget y visitó las escuelas primarias características de Ginebra, donde llevó a cabo trabajos prácticos.

No fue la metodología, sino el conocimiento de la educación parvularia, lo que llevó a María de los Dolores Ballesteros, hermana del inspector Antonio Ballesteros, a solicitar una pensión para mejorar su formación en este nivel ${ }^{4}$. Igual que Julia Morros, había solicitado varias pensiones desde 1928, pero no fue hasta el 9 de abril de 1934 cuando le fue concedida una estancia de tres meses en Francia, Bélgica y Suiza. A esta inspectora le interesaron los métodos usados para enseñar lenguaje y cálculo y la organización de las cantinas escolares. En París, realizó además de estudios en bibliotecas y prácticas de laboratorios, un detenido trabajo en varias escuelas fijándose en cómo se interpretaba en Francia la educación sensorial, motriz y rítmica en el niño, el material escolar y la colaboración familia-escuela. Mención especial merece su estancia en Estrasburgo, donde conoció un método especial de educación de lenguaje. En Bélgica visitó el Instituto Decroly y la escuela que organizó el pedagogo. En Suiza, el cantón de Neufchatel es el centro de sus trabajos, así como diversas escuelas infantiles. Además, en los tres países se detuvo en conocer la preparación profesional y la cultura personal de las educadoras de párvulos, así como el papel social y nacional de las inspectoras de aquellas escuelas.

La educación social de la infancia fue el punto común entre las inspectoras María Cruz Gil y María de los Ángeles Rodríguez. La primera de ellas, Inspectora Jefa de Primera Enseñanza de Soria, había pedido hasta cinco veces ser becada en grupo para mejorar su formación pedagógica desde 1927. No será hasta abril de 1934, como su compañera Ballesteros, cuando recibió confirmación positiva. Visitó centros de enseñanza como Le Maison de Petits o el Instituto Rousseau en Ginebra; la escuela Decroly, Le Jardín des Enfants no14 de la Rue de la Clef en Bruselas o las Escuelas Profesionales de París. Posteriormente pedirá conocer centros italianos de esta misma índole (MINISTERIO DE INSTRUCCIÓN PÚBLICA Y BELLAS ARTES, 1935). Acompañaba a su memoria un trabajo titulado "Función

\footnotetext{
${ }^{4}$ Puede comprobarse a lo largo de su trayectoria como esta inspectora consideraba la educación parvularia atrasada en España y criticaba la situación de los locales en los que se llevaba a cabo la educación de este nivel. Asimismo, reclamaba una mejor formación profesional de las maestras dedicadas a este tipo de educación.
} 
social que la maestra rural puede realizar en el medio en que se encuentra", en el que hablaba de cómo la escuela rural tenía una función social intensa para ayudar a mejorar y transformar las condiciones de vida de la población (esencialmente la femenina). Además, tenía especial interés por mejorar las condiciones de las escuelas y demandaba la necesidad de que los niños fueran educados en la primera infancia, como la inspectora Ballesteros.

Esa función educadora de la escuela elemental también llama la atención de María de los Ángeles Antelo Rodríguez, inspectora que fue becada durante cuatro meses para estudiar la organización escolar en Suiza. Presentó como aval en 1935 un trabajo titulado "Contribución de la escuela a la educación social del niño", en el que reflejaba la importancia de la escuela para preparar al niño como miembro activo de la sociedad. En 1936 le fue concedida una prórroga para terminar su formación y obtener el Certificado de Estudios Pedagógicos de la Universidad de Ginebra.

\section{B) Maestras}

Un total de trece maestras que trabajaban en provincias de la actual región de Castilla y León, también fueron pensionadas en las primeras décadas del siglo XX para formarse fuera de las fronteras españolas. Francia fue el lugar elegido por todas ellas para realizar sus estancias en el extranjero y muchas profesionales habían cursado sus estudios en la Escuela de Estudios Superiores de Magisterio de Madrid (Tabla 2).

Tabla 2 - Maestras nacionales pensionadas por la JAE en Castilla y León (1907-1940)

\begin{tabular}{clccc}
\hline Año/s & Apellidos y nombre & Origen & Destino & Materia \\
\hline $1912-1914$ & Abad Fernández, Carolina & Zamora & FR, B & Educación \\
$1912 / 1918 / 1919$ & Eced y Heydeck, María & Valladolid & FR, B & Educación \\
1912 & $\begin{array}{l}\text { Iglesias Hernández, } \\
\text { Tomasa } \\
\text { Gómez y Sánchez, Ana } \\
\text { María }\end{array}$ & Zamora & FR, B & Educación \\
\hline
\end{tabular}




\begin{tabular}{clccc}
\hline 1913 & $\begin{array}{l}\text { Garayalde y Leunda, } \\
\text { Joaquina }\end{array}$ & Burgos & FR, B & Educación \\
1918/1919 & $\begin{array}{l}\text { Sánchez Tamargo, Amalia } \\
1920-1921\end{array}$ & $\begin{array}{l}\text { León } \\
\text { Alonso y García } \\
\text { Domínguez, María Carmen }\end{array}$ & FR & Educación \\
$1920-1922$ & $\begin{array}{l}\text { Fanjul y Álvarez } \\
\text { Santullano, María Luisa }\end{array}$ & León & FR & Educación \\
1922 & $\begin{array}{l}\text { Ruiz García, Carmen } \\
1924\end{array}$ & Zamora & FR & Educación \\
$1924 / 1925$ & $\begin{array}{l}\text { Camareta Ramirio, Mariana } \\
\text { Luisa }\end{array}$ & Palencia & FR & Educación \\
$1924 / 1925$ & $\begin{array}{l}\text { Higuera Alonso, María de } \\
\text { los Dolores }\end{array}$ & Zamora & FR & Educación \\
1936 & Díez Blanco, María & León & FR & Educación \\
\hline
\end{tabular}

Fuente: Elaboración propia, 2020

Por Real Orden 10 de abril de 1912 se formó un grupo de maestras para hacer una excursión de dos meses a Francia y Bélgica, con el objetivo de estudiar la organización y funcionamiento de las escuelas primarias y las Normales. Dirigió este grupo Luis Álvarez Santullano, Inspector de Primera Enseñanza y lo conformaron diez maestras más que trabajaban en distintos lugares de España, entre las que se encontraban Carolina Abad, María Eced y Tomasa Iglesias.

Estas tres maestras cursaron sus estudios en la primera década de 1900 y habían recibido algunos reconocimientos por su labor al frente de la escuela en sus primeros destinos. Mujeres solteras, con conocimiento del francés y con edades inferiores a los 35 años, las tres maestras se embarcaron en este grupo de profesionales para viajar al extranjero en la primavera de 1912. Defensoras de las visitas a otros países como el medio más eficaz para la regeneración de la escuela patria, pensaban que el estudio de la organización de las escuelas extranjeras, consideradas como modelos dignos de ser imitados, podían hacer de la escuela española centro y base de toda cultura (JUNTA PARA LA AMPLIACIÓN DE ESTUDIOS E INVESTIGACIONES CIENTÍFICAS, 1924a). María Eced presentó como aval para solicitar su ayuda una memoria que resumía las charlas que Cossío había dado en el Museo del Prado y a las que ella misma había asistido antes del viaje. 
La excursión se inició en abril. El grupo comenzó su viaje de estudio en Madrid con una breve estancia para su preparación, del 10 al 17 de abril, en el Museo de Arte y en el Museo Pedagógico Nacional. El día 18 salió el grupo hacia Hendaya, donde visitaron el sanatorio que allí sostenía la ciudad de París. Continuaron su viaje por Burdeos, París y Bélgica (JUNTA PARA LA AMPLIACIÓN DE ESTUDIOS E INVESTIGACIONES CIENTÍFICAS, 1924a).

En los trabajos que presenta Tomasa Iglesias a modo de diario de su viaje, podemos comprobar cómo fueron algunas jornadas de su estancia. En el documento titulado "Viaje de un grupo de maestras. I" (8 de mayo de 1912), la maestra cuenta que por la mañana visitaron en Francia varios museos y por la tarde fueron a una escuela maternal ubicada en Rue de Villejuit número 28 (IGLESIAS, 1912). En ella se fijaron en la práctica del dibujo y la enseñanza de la lecto-escritura. Iglesias reflexiona sobre la diferencia entre la enseñanza en estas escuelas y las españolas, pues no utilizaban renglones, viendo que esta práctica les ayudaba a los niños a aprender a escribir antes. También habla de los trabajos manuales de bordados. Por la noche estuvieron en La Sorbona, escuchando una conferencia sobre los primeros habitantes de París. También visitaron las escuelas decrolyanas y las escuelas profesionales belgas, en las que se fijaron en aspectos de la educación social.

Al volver de la estancia, las maestras muestran el choque de realidad que les produce ver las escuelas españolas y compararlas con las francesas. En la memoria que presenta Tomasa Iglesias a su regreso del viaje, titulada "Otras notas del viaje del grupo de maestras" se percibe cómo la maestra es más consciente de la realidad educativa española en aquel periodo, haciendo alusión a las carencias que existían en los edificios y patios escolares, así como los recursos de los que estaban provistas las escuelas:

La escuela posee siete mesas-bancos antiguos, capaces para 35 alumnas; las matriculadas eran 80; ¿qué hacer en tal apuro? Las mismas niñas compraron sus asientos; pero ¿cómo dibujar y escribir sobre las rodillas? Esta era una gran contrariedad y yo no quería entristecerme al principio; así es que recordando aquellas mesas que vi usar en los Jardines de Infancia extranjeros, sólidas, ligeras, que se podían llevar a cualquier sitio, mandé construir dos de pino. (IGLESIAS, 1913, p. 402) 
La visita al extranjero le ayuda a mejorar su práctica educativa. La maestra resalta a su vuelta la importancia de enseñar a través de un programa lúdico, de trabajar la gimnasia, de realizar excursiones e intercambios entre alumnos, del aprendizaje a través de la observación y de la experimentación o del valor de las colecciones de objetos para el aprendizaje, así como la necesidad de promover la higiene entre el alumnado.

Un segundo grupo de maestras viajó con el mismo fin al año siguiente, en 1913. Dirigido por Matilde García del Real, Inspectora de Primera Enseñanza, en él se encontraban tres profesoras normalistas, una inspectora y cinco maestras. Entre las maestras estaban Joaquina Garayalde y Ana María Gómez y Sánchez.

Joaquina Garayalde y Leunda nació en Villabona (Guipúzcoa) en 1882 y tenía una firme vocación por el Magisterio. Fue una de las alumnas destacadas por la corporación provincial de Guipúzcoa por sus brillantes notas en 1903 (DIPUTACIÓN DE GUIPÚZCOA, 1903). Maestra nacional Superior de Melgar de Fernamental (Burgos) solicitó a la JAE en el curso académico 1912/1913 formar parte de un grupo de maestras para visitar Francia y Bélgica. Antes de realizar este viaje, Garayalde había visitado a título personal escuelas maternales de niñas y adultas en París y Burdeos, hechos que indicaban una preparación aceptable para realizar este viaje y que fueron tenidos en cuenta para la concesión de su solicitud por parte de la JAE (MARÍN, 1990). Ana María Gómez y Sánchez era Maestra Superior desde diciembre de 1901 (JUNTA PARA LA AMPLIACIÓN DE ESTUDIOS E INVESTIGACIONES CIENTÍFICAS, 1913a). Docente en Baltanás (Palencia), también había mostrado desde el inicio de su carrera profesional interés por el conocimiento educativo europeo y la infancia.

El grupo permaneció en Francia y Bélgica dos meses, desde octubre de 1913, visitando escuelas primarias y Normales en Burdeos, Blanguefort, París y Bélgica. A su vuelta, Gómez y Sánchez presentó un trabajo titulado "Escuelas de sordomudos" (31 de octubre de 1913), en el que comentaba la visita realizada a uno de estos centros, en la Rue Saint Simon, y la atención exquisita que las monjas daban al alumnado, así como las condiciones del centro, hechos que resultaban a la maestra significativos para la educación de estos niños. 
Tras el viaje, Garayalde pidió una prórroga de su estancia, aunque no le fue concedida. Siendo ya maestra en Tolosa, realizó una petición para volver como integrante de grupo a conocer el funcionamiento de las escuelas maternales y de párvulos, pero su petición tampoco fue considerada.

Algunas de las maestras referidas, como Carolina Abad o María Eced, solicitaron después de los viajes en grupo ser repetidoras en Francia. Junto a ellas también pidieron esta consideración todas las maestras de la muestra que presentaron su solicitud desde 1918. Con conocimiento del francés y edades comprendidas entre los 18 y los 35 años, las maestras ocuparon este puesto de repetidoras en el país galo. Gracias al convenio suscrito por los Ministros de Instrucción Pública de España y Francia, los "repetidores" de español "daban clases en nuestro idioma en las Escuelas Normales francesas, podían disfrutar de cualquier enseñanza que se impartiera en dichos centros y tenían derecho a residir gratuitamente en los internados de estos, manutención incluida" (SÁNCHEZ, 1988, p.79)

Carolina Abad fue lectora en la Escuela Normal de Maestras de Tarbes (1912-1914) permitiéndola seguir de cerca la labor de las escuelas de párvulos de aquella población y perfeccionarse en el conocimiento del francés; María Eced lo hizo en la Escuela Normal de maestras de Carcassone (1918-1920); Amalia Sánchez, Maestra Superior y en propiedad de la escuela nacional de Valencia de Don Juan (León), solicitó en 1919 la consideración de pensionada para ampliar su formación y conocer el funcionamiento de algunos centros docentes en Francia. Le fue concedida dicha consideración para ser repetidora en la ciudad francesa de Carcassone, una consideración que se constató a través del Real Decreto de 30 de octubre de 1919 (JUNTA PARA LA AMPLIACIÓN DE ESTUDIOS E INVESTIGACIONES CIENTÍFICAS, 1919). El 20 de septiembre de 1920 pidió de nuevo ser repetidora en Mont de Marsan (Francia), solicitud que también le fue concedida por Real Orden de 6 de octubre de 1920. Carmen Alonso y García Domínguez, Maestra Superior de Santa Clara 9 (Zamora), solicitó ser repetidora de Lengua Española en la Escuela Normal de maestras de Aurillac. La pensión le fue concedida en 1920. En aquella estancia, además de realizar labores como repetidora, asistió a las clases de Ciencias Físico-Naturales de aquel centro, por 
haber seguido durante el curso 1917-1918 el de Biología Animal dirigido por Zulueta en el Museos de Ciencias Naturales y en el curso 1916-1917 el de Química, impartido por Lozano en el Museo Pedagógico (JUNTA PARA LA AMPLIACIÓN DE ESTUDIOS E INVESTIGACIONES CIENTÍFICAS, 1920a). En 1921, recién nombrada como Profesora Numeraria de Física, Química e Historia Natural de la Escuela Normal de maestras de Ourense, solicitó una nueva pensión para seguir los cursos de Ciencias Físico-Naturales en la Escuela de Fontenay aux Roses (Francia). María Luisa Fanjul y Álvarez fue repetidora en la Escuela Normal de maestras de Albi entre 1920 y 1921 (JUNTA PARA LA AMPLIACIÓN DE ESTUDIOS E INVESTIGACIONES CIENTÍFICAS, 1921); Carmen Ruiz García, natural de Toro (Zamora), solicitó como Maestra Superior una pensión a la JAE a los 19 años de edad, para perfeccionarse en el estudio de la lengua francesa y en la organización pedagógica de la enseñanza primaria de las escuelas de Francia. La Junta no consideró su solicitud en esta primera ocasión. Un año más tarde, como Maestra Nacional y acreditando que había practicado recién terminada su carrera la enseñanza en la Fundación González Allende, en la materia de Enseñanzas del Hogar, y que tenía suficiente conocimiento del francés solicitó ser repetidora de español. La petición esta vez sí fue considerada y concedida (JUNTA PARA LA AMPLIACIÓN DE ESTUDIOS E INVESTIGACIONES CIENTÍFICAS, 1924b). Viajó a Carcassone por un curso y al año siguiente consiguió ser de nuevo pensionada en la misma figura de repetidora, en la Escuela Mont de Marsan.

Mariana Arrieta Ramirio fue repetidora en París y siguió los cursos superiores de Pedagogía dirigidos por Ferdinand Buissón entre 1924 y 1925 (JUNTA PARA LA AMPLIACIÓN DE ESTUDIOS E INVESTIGACIONES CIENTÍFICAS, 1925a); Luisa Camarero, lo hizo en el Collège de filles de Pamiers y en el Collège de Jeunes Filles (Ariege), entre 1924 y 1926 (JUNTA PARA LA AMPLIACIÓN DE ESTUDIOS E INVESTIGACIONES CIENTÍFICAS, 1925b); María de los Dolores Higuera Alonso desempeñó por un curso la plaza de repetidora de español en el Lycée de filles de Beauvais entre 1924 y 1926 (JUNTA PARA LA AMPLIACIÓN DE ESTUDIOS E INVESTIGACIONES CIENTÍFICAS, 1931); y María Díez Blanco fue designada en 1936 en el Collège de filles de Angulema, en Francia (JUNTA PARA LA AMPLIACIÓN DE ESTUDIOS E INVESTIGACIONES CIENTÍFICAS, 1936a). 


\section{C) Profesoras normalistas}

Junto a las inspectoras y maestras, siete profesoras normalistas que impartían docencia en distintas provincias de la región castellanoleonesa (Tabla 3) viajaron durante el periodo analizado a distintos países con amplia trayectoria en la renovación educativa.

Tabla 3 - Profesoras normalistas pensionadas por la JAE en Castilla y León (1907-1940)

\begin{tabular}{clccc}
\hline Año/s & \multicolumn{1}{c}{ Apellidos y nombre } & Origen & Destino & Materia \\
\hline 1922 & Alfaya López, María & Segovia & FR, B & Educación \\
& Concepción & & & \\
$1922-1925$ & Nogués y Sardá, Dolores & Ávila & FR, B, SU & Educación \\
1925 & Elías y Herrando, Emilia & Segovia & FR, B & Educación \\
1927 & Pablo Colimorio, Teresa de & Valladolid & B & Educación \\
$1927-1936$ & Jiménez Crozat, María & Segovia & FR, B, SU & Educación \\
& Victoria & RUM & \\
1935 & Asenjo García, Victoriana & Soria & FR, B, SU & Educación \\
1935 & Mateos y Mateos, María & Zamora & FR, B, SU, & Educación \\
& Modesta & HO, IT & \\
\hline
\end{tabular}

Fuente: Elaboración propia, 2020

María Concepción Alfaya López era natural de Madrid y fue titulada como Profesora Normalista en 1912. Profesora Numeraria de la Escuela Normal de maestras de León y antigua alumna de la Escuela de Estudios Superiores del Magisterio, tuvo desde sus comienzos una estrecha relación con la JAE. En enero de 1913 solicitaba figurar como agregada en el Centro de Estudios Históricos que dirigía Rafael Altamira. Acompañaba a su instancia una memoria titulada "El Mito y la Historia: su valor educativo". Una vez dentro del Centro y ya como Profesora Numeraria de la Normal de Cuenca, el propio Altamira redactó para ella un informe, en noviembre de 1913, solicitando al Centro de Estudios Históricos que le permitiera continuar con los trabajos emprendidos sobre la cuestión social en España en el siglo XIX (JUNTA PARA LA AMPLIACIÓN DE ESTUDIOS E INVESTIGACIONES CIENTÍFICAS, 1913b). Colaboró en el Centro de Estudios Históricos entre 1910 y 1936, en la sección de Metodología de la Historia Contemporánea. 
En 1922, trabajando en la Normal de Maestras de Segovia, cargo que llevaba ejerciendo desde 1915, solicitaba pensión para estudiar la enseñanza de la Historia en los países de lengua francesa. Su solicitud fue aprobada en noviembre de 1922 y la Junta le concedió una estancia de ocho meses para realizar estudios de Historia en Francia y Bélgica.

En París asistió a las conferencias del Collège de France y a las clases de las Escuelas Normales de Fontenay-aux-Roses y Saint Cloud, informándose de la enseñanza de la Historia en la escuela aneja a la Normal de Maestras y en varias escuelas francesas. Además, visitó otros establecimientos de Educación e Higiene Infantil. En el Museo Pedagógico frecuentó las conferencias semanales de Simon y las llamadas "de los jueves" de controversia pedagógica entre maestras.

En Bélgica, además de visitar varias instituciones de carácter social, se interesó por los trabajos escolares y sociales que, por su afinidad con la historia, le Llamaban la atención. Además, visitó la Université Libre de Bruxelles, la Universidad de Trabajo de Charleroi, la Ecole Normale des Regents, la Menagère Agricole de Lacken, la de Maestras de Brujas y otras escuelas infantiles siguiendo su organización y las prácticas escolares para alumnos normalistas. Su visita a este país le llevó a publicar un libro en 1927 titulado: "La beneficencia de la posguerra en Bélgica. Asistencia y beneficencia”.

Un año después de realizar su viaje, en 1923, quiso hacer extensiva su visita a Suiza, aunque su solicitud le fue denegada. También se le denegó en 1925 una pensión junto a su hermana, la inspectora María de la Paz Alfaya. Juntas habían iniciado el estudio de los bordados populares segovianos en un cursillo destacado en la ciudad en 1924 y teniendo noticia de que se iba a celebrar en Laecken una exposición de artes del hogar, pedían ir a aprender y a exponer su trabajo, aunque esta solicitud no fue considerada. Tampoco se consideró una pensión que solicitó en 1935 para completar sus estudios sobre etnografía y arte popular, así como para estudiar la utilización pedagógica de estos elementos en Italia, Rumanía y Checoslovaquia, países cuya orientación y modalidades folclóricas se necesitaban conocer para enjuiciar el arte popular español, según ella mencionaba. 
Emilia Elías y Herrando cursó los estudios de Magisterio en Madrid y en 1911 ingresó en la Escuela de Estudios Superiores del Magisterio. En 1914 fue nombrada Profesora Numeraria de Geografía de la Escuela Normal de Gerona, en la que ejerció como directora en 1915. Llegó a Segovia en el año 1917 y se mostró activa en el desarrollo y la formación de las maestras de la provincia (MORENO, 2019, p. 200).

En 1925 solicitó consideración de pensionada -y le fue concedida- para ampliar sus estudios pedagógicos en París y Bruselas. Quería conocer el funcionamiento de las Escuelas Normales extranjeras y dentro de ellas la organización de las enseñanzas pedagógicas, visitando las escuelas más importantes. Presentaba como aval un extenso trabajo titulado "La vida nacional y la escuela primaria" (JUNTA PARA LA AMPLIACIÓN DE ESTUDIOS E INVESTIGACIONES CIENTÍFICAS, 1920b). En él reflejaba la urgente necesidad de la atención educativa y la reorganización de la enseñanza de las Normales. En 1929 volvió a solicitar pensión, por cuatro meses, para completar la labor de conocimiento de las direcciones prácticas, los métodos y la organización de las Escuelas Nuevas en dos países considerados por entonces focos de la renovación: Bélgica y Suiza. Pero esta vez, la JAE no consideró su solicitud.

También en la década de 1920 Dolores Nogués y Sardá solicitó varias pensiones. Natural de Montroig (Tarragona) y profesora Numeraria de la Escuela de la Escuela Normal de Maestras de Salamanca, mantuvo relaciones con la JAE desde 1922 a 1932. Habiendo realizado estudios especiales de Economía Doméstica y Labores -a cuya enseñanza se entregaba en dicha escuela-, solicitaba pensión en 1922 para viajar a Europa a conocer estas enseñanzas. Reiteró su petición en 1923 y, en septiembre de ese mismo año, la Junta acordó proponerla por ocho meses como pensionada a Francia, Bélgica y Suiza para estudiar la enseñanza de las labores. Su currículum y el trabajo titulado "Arte e industrias del encaje" fueron clave para que la solicitud de Nogués, ya profesora de la Escuela Normal de Maestras de Ávila, fuera valorada positivamente. Comenzó su viaje en 1924. Permaneció varios días en Orleans y visitó la Escuela Normal de Maestras, dirigida por Bremond, asistiendo a varias sesiones de las clases de "Mánagères", enseñanzas obligatorias en Francia en todos los grados. 
También visitó escuelas en Montargis y Guiers. Se preocupó por el conocimiento de las Escuelas del Hogar en Francia, así como por sus instalaciones y organización pedagógica. En Ginebra asistió al cursillo de vacaciones del Instituto Roussseau dirigido por Bovet y Claparède y enfocado a la educación infantil, moral y profesional.

En Bélgica, se matriculó como alumna libre en el Institut Normal Superior d 'Economia Domèstica Agrícola de Laeken, durante el primer trimestre del curso escolar 1924-1925 y se especializó en Ciencias Alimentarias y Bacterología. En Gante, con el profesor Vandevelde, realizó trabajos prácticos en la Facultad de Medicina. Además, visitó varias escuelas belgas centrada en las enseñanzas del hogar. Los informes positivos de su estancia permitieron que la Junta prorrogara su beca en 1925.

En 1931 solicitó de nuevo pensión para ampliar sus conocimientos en París, en la Société Scientifique d'Hygiène Alimentaire et de Nutrition rationnelle de l'humanité, y visitar escuelas belgas. También lo hizo en 1932 aludiendo que quería visitar centros de Enseñanza del Hogar escandinavos, pero la Junta no le concedió sendas pensiones (JUNTA PARA LA AMPLIACIÓN DE ESTUDIOS E INVESTIGACIONES CIENTÍFICAS, 1932a).

Teresa de Pablo Colimorio, profesora de la Escuela Normal de Maestras de Valladolid solicitó beca en 1926. En septiembre de ese mismo año, la comisión acordó proponerla para ser pensionada y el 14 de enero de 1927 se elevaba la propuesta por tres meses a Bélgica para estudiar la organización y marcha de las escuelas maternales. Como aval, presentó un trabajo de investigación titulado "La escuela. Notas sobre la escuela maternal o de párvulos" de gran interés para conocer la situación de este nivel educativo en la España del primer tercio del siglo XX. Como ella misma explicaba en este estudio "trabajar la formación infantil es superarse en el tiempo y tener un puesto entre los valores reconocidos del mañana" (JUNTA PARA LA AMPLIACIÓN DE ESTUDIOS E INVESTIGACIONES CIENTÍFICAS, 1926, p. 5).

Visitó jardines de infancia en Bruselas y de Amberes y estudió el enlace de estas instituciones con las escuelas primarias. También le interesaron la organización y el funcionamiento de las escuelas froebelianas. Presentó una 
memoria sobre las escuelas maternales belgas, cuyas observaciones daban cuenta del valor de la formación de las maestras en los Kindergarten y la importancia de dichas enseñanzas para la infancia.

María Víctoria Jiménez Crozat obtuvo el título de Maestra de Primera Enseñanza Normal en febrero de 1908. Intentó - sin éxito- conseguir una plaza en Madrid para enseñar a las alumnas del Colegio Nacional de Sordomudos y Ciegos. Quedó en el primer puesto en la oposición de 1909 y fue nombrada Profesora Numeraria de la Sección de Letras de la Escuela Normal de Maestras de Guipúzcoa. Después de su traslado voluntario a Valladolid en 1924, accedería en 1926 a la Escuela Normal de Maestras de Segovia, como Profesora Numeraria de Gramática y Literatura Castellana (MORENO, 2019, p. 289).

Su vinculación con la JAE fue estrecha. En 1922 y 1923 el Ministerio de Instrucción Pública le autorizó para asistir al seminario para formar investigadores del Laboratorio de Geología, dentro del Museo Nacional de Ciencias Naturales. Ingresó en 1931 en la Asociación Española para el progreso de las Ciencias en Valladolid. En su expediente puede comprobarse la estupenda formación de la profesora, pues conocía tres idiomas, algo que no era frecuente en las mujeres de la época.

El 26 de mayo de 1923 solicitó una pensión a Bélgica. Le fue concedida en la sesión de 25 de septiembre, por ocho meses, para estudiar en Bélgica y Suiza la organización de la Enseñanza Doméstica (JUNTA PARA LA AMPLIACIÓN DE ESTUDIOS E INVESTIGACIONES CIENTÍFICAS, 1923). A partir de aquella primera experiencia, Jiménez Crozat solicitaría hasta siete veces más (entre 1924 y 1936) ser pensionada al extranjero. Sus solicitudes fueron admitidas, permitiendo a la Profesora Normalista visitar en la década de 1920 escuelas francesas públicas y privadas, seguir cursos de Enseñanza Doméstica Agrícola en Bruselas, estudiar la organización de la Enseñanza Menagére, conocer los Centros de Educación Doméstica de Lieja y Gante. Durante el periodo republicano, visitó las EscuelasHogar de Rumanía y estuvo en Bucarest. Allí le llegó la noticia del comienzo de la Guerra Civil (MORENO, 2019, p. 291).

Victoriana Asenjo García era Profesora Numeraria de Gramática y Literatura de la Escuela Normal de Jaén. Pidió su primera pensión en 1934, para conocer 
los métodos y procedimientos empleados para la enseñanza de la Lengua en diversas instituciones de París y Bélgica. Tras su traslado a Soria, en 1935, volvió a solicitar la misma pensión ampliando esta vez su viaje a Ginebra, no solo para estudiar la metodología de la Lengua, sino también para profundizar en el conocimiento de las escuelas primarias y de adultos, además de realizar prácticas experimentales. Esta pensión sí le fue concedida (JUNTA PARA LA AMPLIACIÓN DE ESTUDIOS E INVESTIGACIONES CIENTíFICAS, 1935b). En su memoria aparecen dos trabajos titulados "Orientación general sobre la enseñanza del idioma" y un trabajo inédito sobre "Guillén de Castro y Corneille", que le sirvieron de aval para conseguir dicha pensión. En marzo de 1936 pidió una prórroga de un mes para continuar sus estudios, pero esta le fue denegada.

Un caso semejante se presenta con María Modesta Mateos y Mateos. Solicitó pensión en 1934 a Ginebra, pero no fue considerada. Profesora de Lengua y Literatura Castellana en la Escuela Normal de Huelva solicitó esta primera pensión para conocer la organización y funcionamiento de la escuela de párvulos. Presentaba como aval un trabajo titulado "La escuela de párvulos en Madrid", en el que ensalzaba la labor de algunas pensionadas que habían viajado previamente a conocer centros europeos pioneros en la renovación pedagógica y habían traído a las escuelas madrileñas sus aprendizajes. Realizaba este trabajo tras la visita a algunos centros de la capital como el "Grupo Escolar Cervantes" o "Menéndez Pelayo", según acreditaba en su expediente el inspector Antonio Ballesteros y Usano.

En 1935, como Profesora de Paidología y Organización Escolar de la Escuela Normal de Zamora, solicitaba una nueva pensión. Presentaba entonces como aval una memoria que había sido publicada en el mes de mayo en la Revista de Escuelas Normales. La solicitante decía estar interesada por los estudios del lenguaje en párvulos y creía conveniente estar tres meses al lado de Piaget para mejorar su formación. La pensión le fue concedida por acuerdo de sesión 21 de junio de 1935, dentro de un grupo de profesores de Escuelas Normales. Durante dos meses visitaron Francia, Bélgica, Holanda, Suiza e Italia (JUNTA PARA LA AMPLIACIÓN DE ESTUDIOS E INVESTIGACIONES CIENTÍFICAS, 1935c). 


\section{D) Profesoras}

Entre 1914 y 1933 cinco profesoras de diferentes instituciones públicas y privadas enmarcadas en provincias de la actual Castilla y León también fueron pensionadas por la JAE en el extranjero (Tabla 4). En este grupo aparecen biografías muy dispares, como podremos ver a continuación, a pesar de ser algunas de ellas mujeres de notable influencia en la región a lo largo del siglo XX.

Tabla 4 - Profesoras pensionadas por la JAE en Castilla y León (1907-1940)

\begin{tabular}{|c|c|c|c|c|}
\hline Año/s & Apellidos y nombre & Origen & Destino & Materia \\
\hline 1914 & Vega Weter, María Luisa de la & León & $F R, B, S U$ & Educación \\
\hline $\begin{array}{l}1930 / \\
1932\end{array}$ & Fuentes Pérez, Rosario & Valladolid & FR & $\begin{array}{l}\text { Lengua y } \\
\text { Lit }\end{array}$ \\
\hline 1930 & Paredes Marcos, Dionisia & Valladolid & FR & $\begin{array}{l}\text { Lengua y } \\
\text { Lit. }\end{array}$ \\
\hline 1932 & $\begin{array}{l}\text { Martínez Suárez, María de los } \\
\text { Ángeles }\end{array}$ & Zamora & SU & Educación \\
\hline 1933 & González Sarriá, Eloísa & Valladolid & ALEM & $\begin{array}{l}\text { Lengua y } \\
\text { Lit. }\end{array}$ \\
\hline
\end{tabular}

Fuente: Elaboración propia, 2020

María Luisa de la Vega Weter, nacida en Francia, era profesora de la escuela Sierra-Pambley de Villablino ${ }^{5}$. Creada en 1887 gracias a la aportación de Francisco Fernández-Blanco y Sierra-Pambley, que la dotó con la mayor parte de su fortuna personal, y bajo el patronato de Francisco Giner de los Ríos, Gumersindo de Azcárate, y Manuel Bartolomé Cossío, esta institución abría en 1913 su sección de niñas bajo los principios de la ILE, y en ella comenzó a trabajar desde entonces la profesora María Luisa de la Vega Weter.

En 1914 solicitó una pensión individual por cuatro meses a Francia, Bélgica y Suiza, que le fue concedida por Real Orden de 20 de mayo de 1914. Quería estudiar las escuelas del hogar y profesionales de la mujer, especialmente las agrícolas. Para tal fin, la solicitante pidió conocer las Ėcoles Ménagères pero

\footnotetext{
5 Fundación creada con fines educativos en la provincia de León (España) en 1887. La labor de La entidad sin ánimo de lucro tenía el espíritu de la Institución Libre de Enseñanza. Tras el golpe de estado de 1936 la fundación fue incautada por los militares sublevados. En 1979, recién recuperada la democracia en España comenzaron las gestiones para devolverla a los principios pedagógicos que motivaron su creación.
} 
también la de Grignón (Francia). En su expediente alegaba que tenía especial interés por este tema, pues se proponía organizar con carácter benéfico en la aldea en la que vivía desde hacía 6 años (Villablino), la educación de la mujer campesina (JUNTA PARA LA AMPLIACIÓN DE ESTUDIOS E INVESTIGACIONES CIENTÍFICAS, 1914). Había trabajado durante veinte años en la Estación de Biología Marítima de Santander y en el Museo Nacional de Ciencias Naturales. Desde entonces se había dado cuenta de la conveniencia de consagrar la educación de la mujer adaptándola en cada lugar a las profesiones a las que habían de dedicarse las mujeres de clase popular.

Vega Weter ya había mostrado su interés por esta temática años atrás. El Ministerio de Instrucción Pública llegó a nombrar a la profesora, juez de las oposiciones de Profesor de la Escuela del Hogar y Profesional de la Mujer de Madrid y más tarde, a propuesta de la JAE, delegada del Gobierno Español en los Congresos de Círculos de Labradoras ${ }^{6}$ y de Enseñanza del Hogar, que se celebraron en Gante (Bélgica) en julio de 1913. En su solicitud de 1914 presentó como aval una memoria sobre dichas actividades. A pesar de que le fue concedida, no disfrutó de la pensión por estar cuidando de su marido, enfermo en aquel periodo. La pensión se dio por caducada por Real Orden 18 de agosto de 1914. Era una de las pocas mujeres casadas y vinculadas al ámbito pedagógico que pidieron pensión en Castilla y León en estos años.

El caso de Rosario Fuentes Pérez resulta diferente. Hija del militar Julio Fuentes y Forner, obtuvo el título de Maestra Nacional en noviembre de 1917. Se licenció en Filosofía y Letras (Sección de Historia) en la Universidad Central en 1926 y después inició estudios de doctorado con una tesis sobre Historia interna de España en el siglo XIV, a base de "El Libro de los Estados" del Infante Don Juan Manuel y bajo la dirección de Claudio Sánchez Albornoz. En aquellos años, además de preparar una edición de dicha obra para la Colección de Clásicos Castellanos, colaboraba en un vocabulario del infante Don Juan Manuel bajo la dirección de Ramón Menéndez Pidal, director del Centro de Estudios Históricos

\footnotetext{
${ }^{6}$ Los círculos de labradoras nacieron en Estados Unidos. En estos círculos, las labradoras más cultas se reunían para aumentar sus conocimientos y mejorar en su profesión. En el local de cada círculo había una biblioteca y se daban conferencias que las propias labradoras pagaban. Posteriormente, estas experiencias se crearon de forma análoga en otros países como Bélgica.
} 
de la JAE. Además, traducía algunas obras educativas del alemán y del francés de autores como Tiedemann, Sigismund, Lehman o Lacroix. Se interesó también por los estudios filológicos desde los que preparó su cátedra de francés, que logró en 1928. En marzo de ese mismo año presentó un trabajo titulado "La expresión de las relaciones locales en la Lengua francesa. Estudio comparado".

En su expediente se refleja cómo al poco tiempo de ser destinada al Instituto de Segunda Enseñanza de Vigo, en 1928, pidió una excedencia y se reincorporó al cuerpo de catedráticos en 1929. Fue la primera mujer catedrática del Instituto Zorrilla de Valladolid. En la capital vallisoletana solicitó en 1930 la consideración de pensionada (concedida el 21 de octubre de 1930). Su interés era realizar durante nueve meses estudios para ampliar y completar sus conocimientos de francés, centrados en la Lengua y la Literatura francesas del siglo XIV, y poder establecer comparaciones con las españolas.

A su vuelta, en 1932, como Catedrática de Francés en el Instituto de Valladolid y Profesora de Lengua Francesa en el Instituto de Idiomas de la Universidad, solicitaba una nueva pensión a Alemania. El interés de esta estancia era estudiar la organización de la enseñanza alemana, especialmente en lo que a lenguas vivas se refería, conocer los nuevos métodos para introducirlos en las enseñanzas que impartía en sus clases y publicar obras adecuadas a la enseñanza oficial del francés en España (JUNTA PARA LA AMPLIACIÓN DE ESTUDIOS E INVESTIGACIONES CIENTíFICAS, 1932b). Como aval presentaba los cursos que explicaba en su cátedra de francés y un curso de la Universidad, así como los estudios realizados en París y su asistencia al II Congreso Internacional de Profesores de Lenguas Vivas, organizado por la Association des Professeurs des Langues Vivantes de l'Enseigment Public, realizado en 1931 y en el que fue la única española asistente.

La nueva pensión le fue concedida en julio de 1932 para que se desplazara a Berlín por cuatro meses, pero no pudo disfrutar de ella por tenerse que incorporar al Instituto Antonio de Nebrija, recién creado en Madrid.

Las Profesoras Mercantiles Dionisia Paredes Marcos y Eloísa González Sarriá solicitaron pensión desde Valladolid en la década de 1930. La primera, tras terminar su carrera se dedicaba a preparar oposiciones a la Cátedra de Francés. 
En 1929 solicitó una pensión a Francia. Desde hacía tiempo se venía dedicando al estudio de la lengua francesa dirigida por profesores de dicho país simultaneando estos estudios con los de la carrera de Profesora Mercantil. Pedía ser becada al país galo durante tres meses para perfeccionar el idioma y adquirir conocimientos de Filología y Literatura Francesa, pero la pensión no le fue concedida. Ya con la carrera terminada y como oficial del Cuerpo General de Contabilidad del Estado en Valladolid, solicitaba en mayo de 1930 la consideración de pensionada para asistir a los cursos de verano para extranjeros organizados por el Instituto de Tours (JUNTA PARA LA AMPLIACIÓN DE ESTUDIOS E INVESTIGACIONES CIENTÍFICAS, 1930). Esta última solicitud sí le fue concedida a comienzos de junio.

Una situación similar tenía Eloísa González Sarriá. Era Profesora Mercantil y preparaba cátedras de alemán en las escuelas de comercio. Profesora Auxiliar de Alemán del Instituto de Idiomas de la Universidad de Valladolid, en 1933 pidió consideración de pensionada (concedida por acuerdo 29 de abril de 1933) (MINISTERIO DE INSTRUCCIÓN PÚBLICA Y BELLAS ARTES, 1933). Esta profesora viajó durante seis meses a Alemania para renovar y ampliar sus conocimientos del idioma. Realizó sus estudios en Ahlen (Westfalia) en las clases Utersekunda del Liceo, así como en la Escuela Superior femenina. Además, se dedicó a la traducción de "Fausto", una de las obras clave de la literatura universal escrita por Johann Wolfgang von Goethe en el siglo XIX.

El último caso de este grupo de profesoras lo encontramos con María de los Ángeles Martínez Suárez. Era Maestra Superior y profesora de Música de la Fundación institucionista González Allende de Toro (Zamora). Había sido propuesta por unanimidad para este puesto por la JAE, alegando como méritos haber compuesto una colección de cantos escolares y una memoria sobre la enseñanza de la Música en las Escuelas Normales, ser profesora de Piano y haber sido directora de la Sección de Instrucción del Centro Español de Oporto, así como conocer el francés y el portugués (JUNTA PARA LA AMPLIACIÓN DE ESTUDIOS E INVESTIGACIONES CIENTÍFICAS, 1932C). Trabajaba en dicha institución desde 1918, aunque no solicitará una pensión hasta el periodo republicano. 
En 1932 pidió viajar a Suiza por tres meses para ampliar sus estudios de Gimnasia Rítmica en Ginebra con el músico E. Jaques Dalcroze. Alegaba, además de los méritos anteriormente mencionados, haber hecho estudios de Rítmica y dirigido estas enseñanzas en Portugal. Además, había practicado la rítmica en el Instituto-Escuela y había residido por cuenta propia en Francia tres meses, dedicándose a estudiar la organización de la Gimnasia Rítmica y el Canto en las escuelas. Su memoria titulada "La Gimnasia Rítmica como parte integrante de la cultura física y su valor educativo", reflejaba las bondades del método Dalcroze para conectar el ritmo musical con el muscular y potenciar la libertad corporal del niño, alejándola de la rígida gimnasia tradicional:

Considero como un atentado pedagógico el reducir la cultura física escolar a los límites de una gimnasia rígida y severa, autoritaria y militarista, esta es siempre aburrida para el niño y no la ejecuta de buen grado, la hace a disgusto (JUNTA PARA LA AMPLIACIÓN DE ESTUDIOS E INVESTIGACIONES CIENTÍFICAS, 19--, p. 2)

Había escrito artículos sobre las posibilidades de este método en diversos periódicos, revistas pedagógicas y de arte, en los que se dibujaba cómo la profesora entendía que la reorganización de la cultura física en España no pasaba por la reglamentación de esta, sino por la formación de docentes capacitados para tal fin. Esta forma de concebir la educación fue clave para la concesión de su pensión el 24 de junio de 1932.

Durante su estancia en Suiza, visitó el Instituto Jaques-Dalcroze, de Ginebra, donde presenció los cursos de Rítmica de niños y adolescentes y los cursos experimentales y pedagógicos destinados a los profesionales. No pudiendo hacer los cursos de profesionales, por no contar más que con tres meses de concesión de pensión (las matrículas de los cursos profesionales precisaban como mínimo un año escolar), se matriculó y siguió el curso "amateurs" dedicado a los maestros, tomando parte activa.

Además, en la Ecole Secondaire et Supérieure des Jeunes Filles siguió el curso de Gimnasia impartido por Jentzer y dirigió en colaboración con ella diversos ejercicios. Dio clases de Cultura Física con M. Anex; y en la escuela primaria de Malagnon siguió el curso de Educación Física que el Instituto Rousseau destinaba a las maestras. 
Se matriculó como alumna regular en los cursos de Ciencias Pedagógicas de la Universidad de Ginebra y en todos los cursos del Instituto J.J. Rousseau. También trabajó con el doctor Claparède en el laboratorio de Psicología Experimental y con el doctor Walther en el Gabinete de Orientación Profesional de Instituto Rousseau y en Ginebra. Practicó en la Maison des Petits, en la École Internationale y en la Ecole Secondaire et Supérieure des Jeunes Filles, entre otras. Durante su estancia visitó y vio funcionar escuelas maternales, infantiles, primarias, secundarias, superiores y especiales. Además, realizó visitas prácticas a escuelas e instituciones complementarias escolares.

Parece ser que este viaje motivó a la profesora para continuar su formación en el país suizo, pues solicitó una prórroga de la pensión por un curso, en octubre de 1932, para formarse profesionalmente en el Instituto Jaques-Dalcroze, de Ginebra, pero le fue denegada.

\section{E) Puestos no docentes}

Como se ha podido comprobar a lo largo de este análisis, el mayor porcentaje de mujeres pensionadas en el ámbito pedagógico que viajaron gracias a la JAE durante este periodo, se relacionan directamente con el colectivo docente. Sin embargo, otras cuatro mujeres no relacionadas directamente con la docencia también fueron pensionadas en esta región (Tabla 5). Se trata de un grupo de profesionales variado, que atiende a distintos perfiles, como veremos a continuación.

Tabla 5 - Mujeres pensionadas por la JAE en Castilla y León (1907-1940) en puestos no docentes

\begin{tabular}{|c|c|c|c|c|c|}
\hline Año/s & Apellidos y nombre & Origen & Destino & Puesto & Materia \\
\hline $\begin{array}{l}1911- \\
1912\end{array}$ & $\begin{array}{l}\text { Barco Hernández, } \\
\text { Ángela }\end{array}$ & Valladolid & FR & Escritora & Sociología \\
\hline 1928 & $\begin{array}{l}\text { García Delgado, } \\
\text { Gonzala }\end{array}$ & Salamanca & A & $\begin{array}{l}\text { Estudiante de } \\
\text { Medicina }\end{array}$ & Medicina \\
\hline 1936 & $\begin{array}{l}\text { Mendoza y Lasalle, } \\
\text { María Asunción de }\end{array}$ & Valladolid & $\mathrm{FR}, \mathrm{B}$ & $\begin{array}{c}\text { Licenciada en } \\
\text { Filosofía y } \\
\text { Letras }\end{array}$ & Historia \\
\hline 1936 & $\begin{array}{l}\text { Zulueta y Cebrián, } \\
\text { Concepción }\end{array}$ & Burgos & $\mathrm{IT}$ & $\begin{array}{c}\text { Licenciada en } \\
\text { Filosofía y } \\
\text { Letras. } \\
\text { Archivera }\end{array}$ & $\begin{array}{l}\text { Archivos y } \\
\text { Bibliotecas }\end{array}$ \\
\hline
\end{tabular}

Fuente: elaboración propia, 2020 
En este grupo de mujeres resulta relevante la figura de Ángela Barco Hernández. Escritora salmantina, sus obras comienzan a darse a conocer en la primera década del siglo XX. Estos trabajos ya empiezan a desvelar el carácter de la escritora y su afán por revelar la situación que estaba viviendo la mujer española en este periodo?. Solicitó una beca a la JAE en 1911 para estudiar la situación social de la mujer. Alojada en París durante seis meses, pidió pasado el periodo una prórroga que le fue concedida. Alegaba para ello no haber podido estar todo el tiempo que necesitaba recogiendo las observaciones e investigaciones necesarias para los extensos trabajos sociales que estaba realizando. Para acreditar su trabajo, enviaba a la Junta el sumario de una obra que preparaba acerca de "La mujer francesa" y el capítulo referente a "La mujer obrera". La prórroga de nueve meses y cinco días le fue concedida en 1912.

Ese mismo año volvió a solicitar una pensión que le fue concedida por Real Orden de 25 de septiembre de 1912. En esta solicitud, que es toda una declaración de intenciones y una crítica a la situación en la que se encontraba la mujer española de aquel periodo, explicaba que deseaba ampliar sus estudios:

[...] sobre el problema llamado "feminista" en sus aspectos intelectual, literario, obrero y agrícola, en su innovación cultural y tendencias sociales, elemento de suma importancia para la progresiva y útil educación de la mujer que es trascendental fundamento y principal base de toda sociedad humana y civilizada. [...] por su derecho indudable a una independencia económica y ciudadanía igual que el hombre, consideramos de interés, incluso patriótico, ahondar con entera imparcialidad de pensamiento y de miras en esta gran revolución femenina que se anuncia y se acerca de unas fronteras a otras [...]. Creemos asimismo en el cambio radical que representaría de costumbres, supersticiones e ignorancias que sostienen a nuestra raza española en avanzada degeneración moral y atraso incalificable y permanente de cuanto pudiera enriquecerse nuestro país y aumentar en él un bienestar que también se echa de menos si la mujer recibiera educación apropiada que la robusteciese el cuerpo y la inteligencia para ser, a la par que dignísima compañera del hombre en su trabajo y su obra social excelente madre y educadora de sus propios hijos [...] creando de ese modo una raza sana, culta y fuerte (JUNTA PARA LA AMPLIACIÓN DE ESTUDIOS E INVESTIGACIONES CIENTÍFICAS, 1912, p. 1).

\footnotetext{
Un ejemplo de su obra puede leerse en el Cuento Semanal de 1910 o en el artículo titulado "El Hijo", en el que critica las diferencias entre hombres y mujeres y cómo estas se veían abocadas a un único destino, el hogar.
} 
El afán de esta escritora por dejar constancia de la importancia que para la mujer tenía la educación y la crítica a la desatención que el colectivo femenino estaba viviendo en el campo de las Artes, las Ciencias e incluso el Magisterio, aspecto que consideraba un "grandísimo perjuicio para el desarrollo social", queda patente en su expediente. Así se lo contaba a Unamuno en una de sus cartas, en las que cuestionaba el machismo profesional al que se veían sometidas las mujeres.

Francia será otro país considerado para realizar su estancia por María Asunción de Mendoza y Lasalle, aunque con fines diferentes. La licenciada en Filosofía y Letras por la Universidad de Valladolid (promoción 1929-1934) que había sido reconocida con el Premio Extraordinario fin de carrera por sus excelentes calificaciones, estaba realizando por entonces su tesis doctoral. Dirigida por Ballesteros, Catedrático de la Universidad Central y Julián María Rubio, Catedrático de la Universidad de Valladolid, la doctoranda solicitaba en 1936 una pensión para realizar estudios en Francia y Bélgica para investigar sobre el tema de su tesis, la figura del Cardenal Infante Fernando de Austria. Pretendía consultar varios archivos y bibliotecas en Bruselas y París para conocer la intervención del Infante en sus siete años de gobierno en Flandes. Ofrecía a la comisión como aval una parte redactada de su trabajo que había sido posible gracias a la labor realizada en el Archivo de Simancas y la biblioteca provincial de Toledo. La pensión le fue concedida en julio de 1936 por un periodo de seis meses (MINISTERIO DE INSTRUCCIÓN PÚBLICA Y BELLAS ARTES, 1936a). La Guerra Civil no le permitió disfrutar de toda su estancia, pues el 11 de septiembre de 1936 quedaron caducadas todas las pensiones.

Otra licenciada en Filosofía y Letras, Concepción Zulueta y Cebrián, pidió pensión en el mismo periodo que Asunción de Mendoza. Hija del Diplomático Luis de Zulueta y de la maestra y pedagoga Amparo Cebrián, Concepción era funcionaria del Cuerpo Facultativo de Archiveros, Bibliotecarios y Arqueólogos y estaba destinada en el Archivo de la Delegación de Hacienda de Burgos (Centro de Estudios Históricos) antes de la Guerra, según consta en la Gaceta de Madrid con fecha 23 de febrero de 1935. Se encontraba entre las primeras mujeres de la región castellana que llegaron a este cargo antes de la Guerra Civil. Solicitó una 
pensión a Italia (concedida en 1936) para ampliar los estudios y trabajos que venía realizando en el Instituto de Estudios Medievales bajo la dirección del profesor Sánchez Albornoz. Su estancia estaba orientada al estudio de fondos españoles en Archivos y Bibliotecas de Italia, y del Archivo del Vaticano (JUNTA PARA LA AMPLIACIÓN DE ESTUDIOS E INVESTIGACIONES CIENTÍFICAS, 1936b).

En este grupo de mujeres, también se encuentra la estudiante Gonzala García Delgado. Solicitó su primera pensión en 1928. Alumna de cuarto año de la Facultad de Medicina de la Universidad de Salamanca, quería viajar a Alemania para ampliar sus conocimientos de Medicina y realizar investigaciones en Oftalmología. En su expediente alegaba conocer el idioma alemán y tener interés por viajar a la Universidad de Múnich, institución que tenía clínicas de renombre de esta especialidad (JUNTA PARA LA AMPLIACIÓN DE ESTUDIOS E INVESTIGACIONES CIENTÍFICAS, 1928). La Junta le reconoce la consideración de pensionada en la sesión celebrada el 14 de junio de 1928.

\section{2. ¿Qué fue de las mujeres castellanoleonesas pensionadas tras la Guerra Civil?}

El recorrido biográfico por la trayectoria de las mujeres referidas en el anterior apartado nos invita a presentar al lector unas breves notas sobre la trayectoria de estas profesionales tras el disfrute de las pensiones en el extranjero. El objetivo de este punto es analizar las repercusiones que tuvieron los viajes realizados por las profesionales tras la rebelión española de 1936.

El afán renovador de algunas de ellas y su papel activo durante la II República, les costó ser duramente castigadas tras la Guerra. Es el caso de Concepción Zulueta y Cebrián, que fue depurada durante este periodo y expulsada del cuerpo Facultativo de Archiveros.

Junto a Concepción Zulueta, el caso de algunas inspectoras resulta reseñable. Julia Morros Sardá se encontraba en León al comienzo de la depuración. Allí fue suspendida de empleo y sueldo y separada definitivamente de la inspección en 1942. Morros es el ejemplo de una mujer que vio truncada su carrera por el franquismo. El exilio en Argentina primero y la resignación a una oscura carrera docente en provincias, a su regreso, supusieron una de las 
trayectorias representativas de quienes no resultaron vencedoras en el conflicto (CARPINTERO; HERRERO, 2007). Habilitada como maestra, Julia pasó la década de 1940 y gran parte de 1950 destinada en la escuela. En 1957 concursó a una plaza de la Escuela de Magisterio de Guadalajara, como Profesora Numeraria. Allí impartió Física y Química, Ciencias Naturales y Fisiología e Higiene, llegando a ser la directora del centro (POY, 2012, p. 201). Finalmente, consiguió ganar una plaza como Profesora Numeraria de la Escuela de Magisterio "María Díaz Jiménez" de Madrid, de la Sección de Ciencias Naturales, Agricultura y Fisiología e Higiene, donde permaneció como Catedrática y directora hasta su jubilación, el 27 de agosto de 1972. Falleció en Madrid en 1983 (GÓMEZ, 2017).

Semejantes son los casos de María de Los Dolores Ballesteros y Usano y María Cruz Gil y Febrel. La primera de ellas se encontraba ejerciendo el cargo de Inspectora de Primera Enseñanza en León en 1936. Tras ser separada del servicio, por su activismo renovador, se resolvió su expediente de depuración por Orden 8 de marzo de 1951, readmitiéndola al cuerpo - no sin recibir sanciones-. Fue trasladada fuera de Segovia no pudiendo solicitar vacantes en dos años e inhabilitada para ejercer cargos directivos y de confianza. En 1960 fue destinada como inspectora a Salamanca, quedando constancia del cargo en el Boletín Oficial del Estado con fecha 21 de mayo del mismo año.

María Cruz Gil y Febrel recibió en 1937 expediente administrativo de responsabilidades políticas. En su expediente de depuración se le imputaban entre otros cargos: a) su simpatía por el Frente Popular; b) haber cambiado sus ideas derechistas y católicas al advenimiento de la República, "sin duda con el propósito de medrar en su carrera"; y c) haber ocupado cargos oficiales con los gobiernos del Frente Popular. En junio de 1937 fue separada definitivamente del servicio y dada de baja en el escalafón. Su compromiso con la educación social le había llevado a remarcar la importancia de las clases para adultas y a luchar por la educación femenina a través de conferencias, cursos, representaciones teatrales y otras actividades durante el periodo republicano, actividades que no fueron bien vistas por la comisión depuradora. Tras pedir una revisión de su expediente, en 1940 fue repuesta en Soria. Se le imponía como sanción definitiva la suspensión de empleo y sueldo por un año, con abono del tiempo que llevaba 
suspendida, y la inhabilitación para desempeñar cargos directivos y de confianza, como se refleja en el Boletín Oficial del Estado con fecha 26 de agosto de 1940. Moría en 1943.

Otra de sus compañeras, María de la Paz Alfaya, también fue sancionada con traslado fuera de la provincia e inhabilitación para el desempeño de cargos directivos y de confianza en instituciones culturales y de enseñanza durante 5 años según la Orden 30 de octubre de 1940. Se trasladó después como inspectora a Toledo y transcurrido el plazo de cinco años, impugnó la adjudicación de una plaza vacante en la Inspección de Madrid. Al no serle concedida, presentó un recurso de agravios, publicado en el BOE con fecha 7 de noviembre de 1948, que, tras la resolución favorable, le permitió volver a Madrid en 1952. Fue jubilada en 1963.

Su hermana, María Concepción Alfaya López, militante de Izquierda Republicana, ocupaba en 1937 el puesto de Profesora de Metodología de la Historia de la Escuela de Magisterio Primario de Segovia. El proceso depurador la llevó a ser dada de baja y separada del servicio ese mismo año. Decidió entonces trasladarse a Madrid y pedir su reingreso al gobierno republicano. En 1938 se encontraba entre la plantilla de profesores de la Escuela Normal no 2 de Madrid. Tras el fin de la Guerra Civil, en 1941, recibió sanción definitiva. Concepción fue separada del cargo de profesora de Escuela Normal y habilitada como maestra fuera de la provincia de Segovia, sin permiso para solicitar puestos vacantes durante cinco años e inhabilitada para ejercer cargos directivos y de confianza, como se refleja en el Boletín Oficial del Estado con fecha 28 de diciembre de 1941.

Había sido alumna distinguida de Altamira y había ocupado hasta 1936 cargos de responsabilidad, hechos que supusieron un agravio para el gobierno franquista. Otras profesoras normalistas, también sufrieron la represión por su vinculación con el movimiento renovador español del primer tercio del siglo XX. Es el caso de Emilia Elías y Herrando. Casada con el inspector Antonio Ballesteros y Usano, fue colaboradora en la organización de las Colonias Escolares Segovianas y en la Organización de la Biblioteca de la Escuela Normal de Maestras, participando activamente en la vida social y política de la provincia 
durante los años 30. La Guerra obligó a Emilia a permanecer en el exilio. Decidió buscar la libertad en México, donde trabajó en la Escuela Nacional de Maestros, en la Escuela Normal de Pachuca y en la Escuela Nacional Superior (MORENO, 2019, p. 201). En este periodo también asumió la secretaría del Comité Nacional de la Asociación de Mujeres Antifascistas (AMA) y fue nombrada miembro de la Comisión de Auxilio Femenino. Destacada pedagoga y traductora de referentes como Deschamps, Carrier y Decroly, su producción es amplia. Con más de una decena de libros publicados en el exilio hasta su muerte, en 1976, se revela esa apuesta por la educación femenina y la importancia de la formación en todos los niveles aprendida en sus viajes por el extranjero.

La innovación aprendida también fue clave para sancionar a Dolores Nogués y Sardá. La Comisión de Cultura y Enseñanza, de conformidad con lo propuesto por el Rectorado de la Universidad de Salamanca, decidió suspenderla de empleo y sueldo el 18 de noviembre de 1936 (COMISIÓN DE CULTURA Y ENSEÑANZA DE LA JUNTA TÉCNICA DEL ESTADO, 1936). Siendo durante la posguerra devuelta al servicio y como Profesora Numeraria de la Escuela de Magisterio de Valladolid, se le concedió la jubilación en 1950.

Distinto es el caso de otras profesionales que, tras el proceso depurador, fueron reintegradas en sus puestos y llegaron a ocupar cargos relevantes durante la Dictadura. Así puede destacarse el caso de María Asunción de Mendoza y Lasalle, que tras la Guerra ocupaba el cargo de funcionaria del Cuerpo Facultativo de Archiveros, Bibliotecarios y Arqueólogos y estaba destinada en el Archivo General de Simancas en 1950. Su nombre aparece como revisora en varias obras históricas. Otros ejemplos son el de Gonzala García Delgado, que en agosto de 1936 fue nombrada Jefa de Servicios Provinciales de Puericultura en Salamanca (MINISTERIO DE SANIDAD Y ASISTENCIA SOCIAL, 1936) y en 1961 ocupaba el cargo de Médica Puericultora del Estado con destino en el servicio de Higiene Infantil de Salamanca (DIRECCIÓN GENERAL DE SANIDAD, 1961); o Rosario Fuentes Pérez, que en 1936 ocupaba el cargo de Catedrática en el Instituto de Badalona y del Instituto Maragall de Barcelona. Con la depuración docente, fue inhabilitada para el ejercicio de puestos directivos y de confianza, pero al comienzo de la posguerra, como no había cargos contra ella, fue repuesta. Su labor no había sido 
cuestionada, pero se sospechaba de su militancia por estar casada con el izquierdista, Fernando González Rodríguez. En la posguerra fue autora de diferentes libros de enseñanza del francés.

Un ejemplo parecido fue el de María Victoria Jiménez Crozat. En julio de 1936 se encontraba en Bucarest tras prolongar la estancia que le había sido concedida por la JAE. Asumió el cargo de lectora de español en la Academia de Altos Estudios Comerciales e Industriales de Bucarest hasta ser nombrada en 1938 por el primer gobierno de Franco. En 1939 fue suspendida de empleo y sueldo por dos años, trasladada fuera de la provincia de Segovia, con prohibición de solicitar cargos vacantes durante un año, e inhabilitada para el ejercicio de cargos directivos y de confianza en instituciones culturales y de enseñanza. Tras la revisión de su expediente, fue reintegrada en el servicio el 7 de septiembre de 1942. El Ministerio de Educación Nacional, a propuesta del de Asuntos Exteriores, nombró a Jiménez Crozat el 9 de noviembre jefa de la Misión Cultural del Estado Español en Rumanía y encargada de los Cursos de Español en Centros de Enseñanza Superior y Media y en Escuelas Normales. Cesó de su cargo en 1945, con obligación de reintegrarse a su plaza en Segovia el 1 de marzo de ese mismo año (Moreno, 2019, p. 291) y se jubiló el 6 de septiembre de 1950, como Profesora Numeraria de la Escuela de Magisterio de Segovia.

Especial atención merece el caso de las inspectoras Adelaida Díez, que participó en tribunales de plaza durante la posguerra, apareciendo publicados sus llamamientos en el Boletín Oficial del Estado de 12 de noviembre de 1953 y 25 de julio de 1954; y Cándida Cadenas Campos, que ingresó en 1934 en la Sección Femenina de Falange y fue uno de los exponentes de la Educación Física femenina durante la dictadura franquista. Su labor al servicio del Régimen para la instrucción física femenina fue reconocida por la propia Pilar Primo de Rivera.

También, tras la Guerra, continúan en el servicio Dionisia Paredes Marcos, que en 1967 presentaba una solicitud para acceder a plazas vacantes de funcionarios técnico-administrativos con carácter de adjuntos (MINISTERIO DE LA GOBERNACIÓN, 1967); Carmen Alonso y García Domínguez, que en 1958 se encontraba en la tercera categoría del escalafón de docentes numerarios de Escuelas de Magisterio; Eloísa González Sarriá, que era admitida en 1943 a las 
oposiciones entre auxiliares a la Cátedra de Alemán vacante en la Escuela Profesional de Comercio de Cádiz (MINISTERIO DE EDUCACIÓN NACIONAL, 1943) y un año más tarde en la Escuela Profesional de Comercio de Palma de Mallorca (MINISTERIO DE EDUCACIÓN NACIONAL, 1944); o María de los Ángeles Antelo Rodríguez, que el 14 de noviembre de 1953 y el 16 de agosto de 1961 en el Rectorado de Salamanca aparece como vocal de los tribunales de oposición. Estaba destinada como inspectora en Salamanca en 1960 (MINISTERIO DE EDUCACIÓN NACIONAL, 1960).

Algunas maestras, también siguieron en activo durante estos años. Es el caso de Teresa de Pablo Colimorio. Su nombre aparece en los informes de los estudiantes de magisterio expedientados en Sevilla con la firma de profesora normalista durante la Guerra. Se encontraba desde hacía años en la Junta de Gobierno de la Escuela Normal de Maestros que dirigía Luis Paunero Ruiz. También lo es el de Tomasa Iglesias Hernández, que fue una de las precursoras de la Asociación Provincial de Maestros Católicos de Salamanca en 1935 y ocupaba en sus inicios el cargo de vicetesorera. Fue ascendida a la primera categoría del escalafón de maestras nacionales de enseñanza primaria en 1954. Su compañera Amalia Sánchez Tamargo, se encontraba en 1943 en la 5o categoría de la plantilla del Magisterio Nacional femenino.

Pocos datos se conocen en cambio de la trayectoria de casi una decena de las maestras que fueron pensionadas y no se ha destacado su biografía en la historiografía contemporánea, como es el caso de María Luisa Fanjul, Carmen Ruiz, Mariana Arrieta Ramirio, Luisa Camarero, María de los Dolores Higuera, María Díez, Carolina Abad Fernández, María Eced, Ana María Gómez o Joaquina Garayalde. Tampoco se conocen muchos datos sobre otras pensionadas como María Luisa de la Vega Weter, que ha sido considerada por muchos historiadores como una de las musas de la ILE en sus comienzos, llegando a tener el afecto de Giner y Cossío; o Victoriana Asenjo García, Profesora Numeraria de Metodología de la Lengua en la Escuela Normal de Magisterio Primario de Soria en 1936. Su obra "la enseñanza del idioma en el extranjero" fue declarada de utilidad pública y de mérito en su carrera en septiembre de ese mismo año. Según Wenceslao Roces, Director General de Primera Enseñanza, la labor de la 
profesora en aquellos años era laudable y revelaba el interés que la misma ponía en la enseñanza del idioma en el extranjero habiendo recogido el fruto alcanzado en sus investigaciones realizadas con motivo de su pensión en el extranjero (MINISTERIO DE INSTRUCCIÓN PÚBLICA Y BELLAS ARTES, 1936b).

\section{Discusión y conclusiones}

Las mujeres de la región castellanoleonesa becadas por la JAE desde el ámbito pedagógico formaban parte de una generación de profesionales caracterizada por el afán de renovar la educación española y por la necesidad de cambiar la realidad que vivía el país en aquel primer tercio del siglo XX. La mayoría de estas mujeres eran solteras y tenían edades inferiores a los treinta y cinco años, dos aspectos que les permitieron disfrutar del aprendizaje en el extranjero y preocuparse únicamente de su mejora profesional.

Se trataba de un colectivo de mujeres preparadas - algunas de ellas conocían hasta tres idiomas - y tenían especial interés por la evolución social de la mujer y su educación. El contexto francés, el belga y el suizo (especialmente el primero), fueron los destinos a los que recurrieron más del $85 \%$ de las profesionales. Pensionadas en grupo o de forma individual, las profesionales se interesaron por la práctica educativa y el funcionamiento y la organización escolar. Algunas de ellas, llevaron después las enseñanzas aprendidas al aula e intentaron cambiar la realidad que se presentaba en las escuelas del momento, como podemos ver en el caso de algunas maestras e inspectoras. Sus ejemplos son clave para ver que la JAE apostaba por la positivización del trabajo y no por la emancipación femenina.

Sin embargo, la depuración llevada a cabo en España en 1936 afectó de forma visible a aquellas mujeres que querían romper con la desigualdad política, social y profesional a la que se había visto sometido el colectivo femenino tradicionalmente, liberándose de la opresión del patriarcado y tratando de ser visibles en el espacio público. Algunas de las profesionales que aparecen en la muestra utilizada para este estudio, ocuparon cargos de gran relevancia en el periodo republicano y tuvieron relaciones cercanas con el institucionismo. Eran mujeres independientes y activas, aspectos que las llevaron a sufrir una terrible 
represión y en el peor de los casos, a ser expulsadas de sus respectivos cuerpos profesionales.

Muchas de las profesionales fueron al comienzo de la Guerra sancionadas con la suspensión de empleo y sueldo y el traslado forzoso. Si bien estas sanciones no pueden compararse con la expulsión del cuerpo docente, las penas de cárcel o las ejecuciones extrajudiciales (que sufrieron otros profesionales), supusieron serias consecuencias para las protagonistas. Que a finales de los años treinta una mujer quedara sin ingresos, suponía volver a la dependencia familiar. Además, el traslado de centro llevaba consigo una ruptura total tanto a nivel familiar como profesional. En este último sentido, es importante cuestionarnos cómo serían recibidas en los nuevos centros de trabajo por sus propios compañeros (simpatizantes del Régimen y conocedores de su situación), incluso el rechazo social al que se vieron sometidas en las nuevas localidades de destino. El exilio tanto interior como exterior significó un aislamiento y desarraigo nada desdeñable en sus trayectorias vitales y profesionales. El silencio, su único pasaporte para sobrevivir en una España radicalmente distinta a la Europa que habían conocido en sus viajes.

Otras, menos significadas, fueron tras la purga reintegradas de nuevo en sus puestos y distinguidas por la Falange, llegando a ocupar puestos de poder durante la Dictadura, como es el caso de la inspectora Cándida Cadenas. Esta realidad, nos invita a pensar que - salvo los casos que comentábamos anteriormente-la incidencia de muchas de estas pensionadas en la vida política y cultural española durante la década de 1930 no fue relevante. Es más, en muchas de sus biografías puede comprobarse que, tras realizar los viajes al extranjero, algunas volvieron a España y se dedicaron a la función materna, respondiendo de este modo sus perfiles a la perspectiva regeneracionista "lampedusiana" que adecuaba el cliché clásico femenino a los nuevos tiempos: una mujer más instruida que sirviera mejor al hombre y a sus hijos (BALLARÍN, 1989).

Precisamente serán sus ejemplos reveladores de cómo las trayectorias femeninas quedan en muchos casos apartadas del espacio público, a pesar de haber seguido similares caminos que las masculinas, por las funciones 
tradicionalmente asignadas a este género (KURTZ, 2016), corroborando estos casos la teoría de la incidencia difusa de las pensiones, mencionada por Marín (1990).

Además, esta conclusión también se presta a la reflexión citada en Sonlleva y Sanz (2020), que alude a que el grupo de mujeres vinculadas con la educación durante este periodo del primer tercio del siglo XX era un colectivo complejo, en el que convivían diversas ideologías e intereses. El compromiso mostrado por el conocimiento educativo europeo de estas mujeres no estaba directamente ligado con la ideología renovadora en todos los casos.

Lo que sí comparten todas ellas es la apuesta decidida por la ruptura con el modelo de mujer pasiva, sin inquietudes profesionales y alejada de la vida pública, que se presentaba en la España de finales del siglo XIX. Además, en los expedientes de muchas de ellas se hace visible la inquietud que tenían por conocer el papel y la relevancia social de la mujer educadora en los países que visitaron, un hecho que revela su resistencia a la invisibilidad y la necesidad que tenían de ser reconocidas profesionalmente en España.

No queremos terminar este estudio sin presentar algunas limitaciones. La falta de documentación en muchos casos, sobre algunas trayectorias biográficas analizadas, no nos permite presentar una versión tan completa como nos gustaría de las trayectorias de las profesionales antes y después de sus viajes fuera de las fronteras españolas. Quizá, el trabajo con relatos cruzados o archivos personales de las protagonistas del estudio permitiría arrojar nuevos datos sobre esta investigación. Desde las conclusiones mostradas, también creemos conveniente mencionar que sería oportuno poner en discusión los datos extraídos con los de aquellos hombres que fueron pensionados en esta misma región durante el periodo analizado. Esta comparativa podría ser clave para conocer si la muestra masculina se comportó igual que la femenina, cuál fue la implicación de los hombres en la renovación pedagógica de la región y qué consecuencias tuvo para ellos la puesta en práctica de conocimientos extranjeros en el proceso depurador, siendo el estudio concluyente para poder trabajar una perspectiva de género completa. 


\section{Referências}

ALCALÁ, Paloma; MAGALLÓN, Carmen. Avances, ruptura y retrocesos: mujeres en las ciencias experimentales en España (1907-2005). In: ROMERO, Ana; SANTESMASES, María Jesús. (coords.). Cien años de política científica en España. Bilbao: Fundación BBVA, 2008. p. 141-169.

ARAQUE, Natividad. Las primeras mujeres catedráticas de institutos de enseñanza secundaria en España durante la dictadura de Primo de Rivera y su relación con la JAE. En LÓPEZ, Leoncio. (dir.): Aulas modernas: nuevas perspectivas sobre las reformas de la enseñanza secundaria en la época de la JAE (1907-1939). Madrid: Dykinson, 2014. p. 179-214.

BALLARÍN DOMINGO, Pilar. La educación de la mujer española en el siglo XIX. Historia de la Educación, Salamanca, n. 8, p. 245-260, 1989.

CARPINTERO, Helio; HERRERO, Fania. La Junta para Ampliación de Estudios y el desarrollo de la psicología española. Asclepio, Madrid, n. 2, p.181-212, 2007.

COLMENAR, María del Carmen. Aportaciones pedagógicas de las primeras mujeres becadas por la junta para la ampliación de estudios e investigaciones científicas. In: SÁNCHEZ, Felicidad; ALEJO, Francisco Javier; CALVO, Gaspar Félix; LUCERO, Manuel; ORIA, María Rosa; IGLESIAS, Enrique. (coords).

Relaciones internacionales en la historia de la educación: junta para la ampliación de estudios e investigaciones científicas (1907-2007): XIV coloquio de historia de la educación, Guadalupe (Cáceres) del 25 al 28 de junio de 2007: volumen 1. Cáceres: Sociedad Española de Historia de la Educación, Departamento de Ciencias de la Educación de la Universidad de Extremadura, 2007. p. 77-91.

COMAS, Francesca. Pensiones pedagógicas e innovación educativa en España. Aportaciones a un modelo de estudio a través del caso de Baleares. Revista de Educación, Madrid, p. 91-115, 2007. Numero extraordinario.

COMISIÓN DE CULTURA Y ENSEÑANZA DE LA JUNTA TÉCNICA DEL ESTADO. Boletín Oficial del Estado. [S.L.], 21 nov. 1936.

DELGADO, María Ángeles; LÓPEZ, José Damián. Maestras y profesoras del área de ciencias naturales en los focos de renovación de pedagógica de las primeras décadas del siglo XX. In: SÁNCHEZ, Felicidad; ALEJO, Francisco Javier; CALVO, Gaspar Félix; LUCERO, Manuel; ORIA, María Rosa; IGLESIAS, Enrique. (coords):

Relaciones internacionales en la historia de la educación: junta para la ampliación de estudios e investigaciones científicas (1907-2007): XIV coloquio de historia de la educación, Guadalupe (Cáceres) del 25 al 28 de junio de 2007: volumen 1. Cáceres: Sociedad Española de Historia de la Educación, Departamento de Ciencias de la Educación de la Universidad de Extremadura, 2007. p. 93-105. 
DIPUTACIÓN DE GUIPÚZCOA. Comisión provincial de la Excma. Diputación de Guipúzcoa del segundo semestre de 1903, Guipúzcoa.

DIRECCIÓN GENERAL DE SANIDAD. Boletín Oficial del Estado, 26 de mayo de 1961.

FLECHA GARCÍA, Consuelo. La Inspección de primera enseñanza en la España del primer tercio del siglo XX: modelos, contextos y protagonistas. Historia Caribe, Santander, v. 13, n. 33, p. 179-217, 2018.

GARCÍA, Carmen. Las psicólogas españolas y la Junta de Ampliación de Estudios: olvidos y exilios. In: SÁNCHEZ, Felicidad; ALEJO, Francisco Javier; CALVO, Gaspar Félix; LUCERO, Manuel; ORIA, María Rosa; IGLESIAS, Enrique. (coords): Relaciones internacionales en la historia de la educación: junta para la ampliación de estudios e investigaciones científicas (1907-2007): XIV coloquio de historia de la educación, Guadalupe (Cáceres) del 25 al 28 de junio de 2007: volumen 1. Cáceres: Sociedad Española de Historia de la Educación, Departamento de Ciencias de la Educación de la Universidad de Extremadura, 2007. p. 133-140.

\section{GARCÍA MARTÍNEZ, Eladio. Algunas notas escolares de Francia, Bélgica y Suiza.} Madrid: Junta para la Ampliación de Estudios e Investigaciones Científicas, 1924.

GÓMEZ ORFANEL, German. La Junta para la ampliación de estudios y su política de pensiones en el extranjero. Revista de Educación, Madrid, n. 243, p. 28-47, 1976

GÓMEZ SAN MIGUEL, Eva. Inspectoras de primera enseñanza en el primer tercio del siglo XX. 2017. Tesis (Doctorado en Educación) - Madrid, Universidad Complutense de Madrid, 2017.

HERNÁNDEZ, José María. Alice Pestana, becaria de la Junta para la Ampliación de Estudios en Portugal. In: SÁNCHEZ, Felicidad; ALEJO, Francisco Javier; CALVO, Gaspar Félix; LUCERO, Manuel; ORIA, María Rosa; IGLESIAS, Enrique. (coords): Relaciones internacionales en la historia de la educación: junta para la ampliación de estudios e investigaciones científicas (1907-2007): XIV coloquio de historia de la Educación, Guadalupe (Cáceres) del 25 al 28 de junio de 2007: volumen 2. Cáceres: Sociedad Española de Historia de la Educación, Departamento de Ciencias de la Educación de la Universidad de Extremadura, p. 103-112, 2007.

IGLESIAS HERNÁNDEZ, Tomasa. Viaje de un grupo de maestras (II). Madrid: Archivo de la Junta para la Ampliación de Estudios e Investigaciones Científicas (JAE/79-34, Memoria I-2), 1912. 
IGLESIAS HERNÁNDEZ, Tomasa. Otras notas. Madrid: Junta para la Ampliación de Estudios e Investigaciones Científicas, 1913.

JUNTA PARA LA AMPLIACIÓN DE ESTUDIOS E INVESTIGACIONES CIENTÍFICAS. Expediente personal de Ana María Sánchez y Gómez. Madrid: Archivo de la Junta para la Ampliación de Estudios e Investigaciones Científicas (JAE/70-637), 1913a.

JUNTA PARA LA AMPLIACIÓN DE ESTUDIOS E INVESTIGACIONES CIENTÍFICAS. Expediente personal de Ángela Barco Hernández. Madrid: Archivo de la Junta para la Ampliación de Estudios e Investigaciones Científicas (JAE/15-92), 1912.

JUNTA PARA LA AMPLIACIÓN DE ESTUDIOS E INVESTIGACIONES CIENTÍFICAS. Expediente personal de Amalia Sánchez Tamargo. Madrid: Archivo de la Junta para la Ampliación de Estudios e Investigaciones Científicas (JAE/134-254), 1919.

JUNTA PARA LA AMPLIACIÓN DE ESTUDIOS E INVESTIGACIONES CIENTÍFICAS. Expediente personal de Cándida Cadenas Campos. Madrid: Archivo de la Junta para la Ampliación de Estudios e Investigaciones Científicas (JAE/26-47), 1935a.

JUNTA PARA LA AMPLIACIÓN DE ESTUDIOS E INVESTIGACIONES CIENTÍFICAS. Expediente personal de Carmen Alonso y García Domínguez. Madrid: Archivo de la Junta para la Ampliación de Estudios e Investigaciones Científicas (JAE/5229), 1920 .

JUNTA PARA LA AMPLIACIÓN DE ESTUDIOS E INVESTIGACIONES CIENTÍFICAS. Expediente personal de Carmen Ruiz García. Madrid: Archivo de la Junta para la Ampliación de Estudios e Investigaciones Científicas (JAE/129-570), 1924b.

JUNTA PARA LA AMPLIACIÓN DE ESTUDIOS E INVESTIGACIONES CIENTÍFICAS. Expediente personal de Concepción Zulueta y Cebrián. Madrid: Archivo de la Junta para la Ampliación de Estudios e Investigaciones Científicas (JAE/153-42), $1936 b$.

JUNTA PARA LA AMPLIACIÓN DE ESTUDIOS E INVESTIGACIONES CIENTÍFICAS. Expediente personal de Dionisia Paredes Marcos. Madrid: Archivo de la Junta para la Ampliación de Estudios e Investigaciones Científicas (JAE/110-92), 1930.

JUNTA PARA LA AMPLIACIÓN DE ESTUDIOS E INVESTIGACIONES CIENTÍFICAS. Expediente personal de Dolores Nogués y Sardá. Madrid: Archivo de la Junta para la Ampliación de Estudios e Investigaciones Científicas (JAE/106-110), 1932a.

JUNTA PARA LA AMPLIACIÓN DE ESTUDIOS E INVESTIGACIONES CIENTÍFICAS. Trabajo de Emilia Elías y Herrando. Madrid: Archivo de la Junta para la 
Ampliación de Estudios e Investigaciones Científicas (JAE/46-24, Memoria E-6), $1920 b$.

JUNTA PARA LA AMPLIACIÓN DE ESTUDIOS E INVESTIGACIONES CIENTÍFICAS. Expediente personal de Gonzala García Delgado. Madrid: Archivo de la Junta para la Ampliación de Estudios e Investigaciones Científicas (JAE/61-192), 1928.

JUNTA PARA LA AMPLIACIÓN DE ESTUDIOS E INVESTIGACIONES CIENTÍFICAS. Expediente personal de Luisa Camarero y Fernández. Madrid: Archivo de la Junta para la Ampliación de Estudios e Investigaciones Científicas (JAE/28-120), 1925b.

JUNTA PARA LA AMPLIACIÓN DE ESTUDIOS E INVESTIGACIONES CIENTÍFICAS. Expediente personal de María Concepción Alfaya López. Madrid: Archivo de la Junta para la Ampliación de Estudios e Investigaciones Científicas (JAE/4-182), $1913 b$.

JUNTA PARA LA AMPLIACIÓN DE ESTUDIOS E INVESTIGACIONES CIENTÍFICAS. Expediente personal de María de los Ángeles Martínez Suárez. Madrid: Archivo de la Junta para la Ampliación de Estudios e Investigaciones Científicas (JAE/96-387), 1932c.

JUNTA PARA LA AMPLIACIÓN DE ESTUDIOS E INVESTIGACIONES CIENTÍFICAS. Trabajo de María de los Ángeles Martínez Suárez. Madrid: Archivo de la Junta para la Ampliación de Estudios e Investigaciones Científicas (JAE/96-387, Memoria M-71), [19--].

JUNTA PARA LA AMPLIACIÓN DE ESTUDIOS E INVESTIGACIONES CIENTÍFICAS. Expediente personal de María de los Dolores Higuera Alonso. Madrid: Archivo de la Junta para la Ampliación de Estudios e Investigaciones Científicas (JAE/78122), 1931.

JUNTA PARA LA AMPLIACIÓN DE ESTUDIOS E INVESTIGACIONES CIENTÍFICAS. Expediente personal de María Díez Blanco. Madrid: Archivo de la Junta para la Ampliación de Estudios e Investigaciones Científicas (JAE/43-122), 1936a.

JUNTA PARA LA AMPLIACIÓN DE ESTUDIOS E INVESTIGACIONES CIENTÍFICAS. Expediente personal de María Eced y Heydeck. Madrid: Archivo de la Junta para la Ampliación de Estudios e Investigaciones Científicas (JAE/46-1), 1924a.

JUNTA PARA LA AMPLIACIÓN DE ESTUDIOS E INVESTIGACIONES CIENTÍFICAS. Expediente personal de María Luisa de la Vega Weter. Madrid: Archivo de la Junta para la Ampliación de Estudios e Investigaciones Científicas (JAE/148-139), 1914. 
JUNTA PARA LA AMPLIACIÓN DE ESTUDIOS E INVESTIGACIONES CIENTÍFICAS. Expediente personal de María Luisa Fanjul y Álvarez Santullano. Madrid: Archivo de la Junta para la Ampliación de Estudios e Investigaciones Científicas (JAE/50-24), 1921.

JUNTA PARA LA AMPLIACIÓN DE ESTUDIOS E INVESTIGACIONES CIENTÍFICAS. Expediente personal de María Modesta Mateos y Mateos. Madrid: Archivo de la Junta para la Ampliación de Estudios e Investigaciones Científicas (JAE/97-444), 1935c.

JUNTA PARA LA AMPLIACIÓN DE ESTUDIOS E INVESTIGACIONES CIENTÍFICAS. Expediente personal de María Victoria Jiménez Crozat. Madrid: Archivo de la Junta para la Ampliación de Estudios e Investigaciones Científicas (JAE/81-29), 1923.

JUNTA PARA LA AMPLIACIÓN DE ESTUDIOS E INVESTIGACIONES CIENTÍFICAS. Expediente personal de Mariana Arrieta Ramirio. Madrid: Archivo de la Junta para la Ampliación de Estudios e Investigaciones Científicas (JAE/11-550), 1925a.

JUNTA PARA LA AMPLIACIÓN DE ESTUDIOS E INVESTIGACIONES CIENTÍFICAS. Expediente personal de Rosario Fuentes Pérez. Madrid: Archivo de la Junta para la Ampliación de Estudios e Investigaciones Científicas (JAE/57-421), 1932b.

JUNTA PARA LA AMPLIACIÓN DE ESTUDIOS E INVESTIGACIONES CIENTÍFICAS. Trabajo de Teresa de Pablo Colimorio. Madrid: Archivo de la Junta para la Ampliación de Estudios e Investigaciones Científicas (JAE/109-2, Memoria P-1), 1926.

JUNTA PARA LA AMPLIACIÓN DE ESTUDIOS E INVESTIGACIONES CIENTÍFICAS. Expediente personal de Victoriana Asenjo García. Madrid: Archivo de la Junta para la Ampliación de Estudios e Investigaciones Científicas (JAE/12-580), 1935b.

KURZ, Robert. El colapso de la modernización. Buenos Aires: Marat, 2016.

LEMUS, Encarnación. La experiencia americana de las pensionadas de la JAE a través de su correspondencia. Arenal: Revista de historia de las mujeres, Granada, v. 26, n.2, p. 541-574, 2019.

MAGALLÓN, Carmen. El laboratorio Foster de la Residencia de Señoritas. Las relaciones de la JAE con el International Institute for Girls in Spain, y la formación de las jóvenes científicas españolas. Asclepio: Revista de historia de la medicina y de la ciencia, Madrid, v. 59, n. 2, p. 37-62, 2007a.

MAGALLÓN, Carmen. La JAE y las pioneras españolas en las ciencias. In: PUIGSAMPER, Miguel Ángel. (ed.). Tiempos de investigación: JAE-CSIC, cien años de 
ciencia en España. Madrid: Consejo Superior de Investigaciones Científicas, 2007b. p. 221-228.

MARÍN, Teresa. La renovación pedagógica en España (1907-1936). Madrid: Centro Superior de Investigaciones Científicas, 1990.

MARÍN, Teresa. Mujeres de la JAE represaliadas por el franquismo. In: GARCÍA, José; SÁNCHEZ, José María (coords.). 100 JAE: la Junta para la Ampliación de Estudios e Investigaciones Científicas en su centenario. II CONGRESO

INTERNACIONAL, 2., feb. 2008. Actas [...].Madrid: Fundación Francisco Giner de los Ríos: Institución Libre de Enseñanza: Publicaciones de la Residencia de Estudiantes, 2010. Tomo I. p. 354-383. Temas generales. Ciencia en la JAE.

MENDOZA, Irene. Mujeres pensionadas en Francia por la JAE. Algunas especificidades. In: La Segona República: cultures i projectes polítics: congrés Internacional d'Història. Bellaterra: Depósito digital de documentos de la Universidad Autónoma de Barcelona, 2016. p. 1-16.

MINISTERIO DE EDUCACIÓN NACIONAL. Boletín Oficial del Estado, Madrid, 30 nov. 1943.

MINISTERIO DE EDUCACIÓN NACIONAL. Boletín Oficial del Estado, Madrid, 2 enero 1944.

MINISTERIO DE EDUCACIÓN NACIONAL. Boletín Oficial del Estado, Madrid, 21 mayo 1960.

MINISTERIO DE LA GOBERNACIÓN. Resolución de la Jefatura Superior del Servicio Nacional de Inspección y Asesoramiento de las Corporaciones Locales por las que se publica la relación de aspirantes al concurso convocado por Orden de 23 de mayo de 1967 para provisión de plazas vacantes de funcionarios técnico-administrativos con el carácter de adjuntos y se cita a dichos aspirantes para la práctica de pruebas de acuerdo con la base tercera de dicha convocatoria. Boletín Oficial del Estado, Madrid, n. 249, p. 14242, 18 oct. 1967.

MINISTERIO DE INSTRUCCIÓN PÚBLICA Y BELLAS ARTES. Real Decreto de 11 de enero de 1907. Gaceta de Madrid, Madrid, v. 246, n. 15, p. 165-166, 15 enero 1907.

MINISTERIO DE INSTRUCCIÓN PÚBLICA Y BELLAS ARTES. Real Decreto de 15 de junio de 1907. Gaceta de Madrid, Madrid, v. 246, n. 173, p. 1140, 22 jun. 1907b.

MINISTERIO DE INSTRUCCIÓN PÚBLICA Y BELLAS ARTES. Real Decreto de 7 de marzo de 1913. Gaceta de Madrid, Madrid,13 mar. 1913.

MINISTERIO DE INSTRUCCIÓN PÚBLICA Y BELLAS ARTES. Orden Ministerial de 10 de mayo de 1933. Gaceta de Madrid, Madrid, 10 mayo 1933. 
MINISTERIO DE INSTRUCCIÓN PÚBLICA Y BELLAS ARTES. Orden Ministerial de 24 de abril de 1935. Gaceta de Madrid, Madrid, 24 abr.1935.

MINISTERIO DE INSTRUCCIÓN PÚBLICA Y BELLAS ARTES. Orden Ministerial de 23 de julio de 1936b. Gaceta de Madrid, Madrid, 23 de jul. 1936a.

MINISTERIO DE INSTRUCCIÓN PÚBLICA Y BELLAS ARTES. Gaceta de Madrid, Madrid,19 sept. $1936 \mathrm{~b}$.

MINISTERIO DE SANIDAD Y ASISTENCIA SOCIAL. Gaceta de Madrid, n.229, p.1280, Madrid,16 ago. 1936.

MORENO YUSTE, Juan Manuel. Segovia 1900-1936: diccionario biográfico. Segovia: Real Academia de Historia y Arte de San Quirce, 2019.

NúÑEZ, Marina; REBOLLO, María José. El delantal y la probeta: las enseñanzas del hogar, una tradición renovada por las becarias de la Junta de Ampliación de Estudios. In: SÁNCHEZ, Felicidad; ALEJO, Francisco Javier; CALVO, Gaspar Félix; LUCERO, Manuel; ORIA, María Rosa; IGLESIAS, Enrique. (coords). Relaciones internacionales en la historia de la educación: junta para la ampliación de estudios e investigaciones científicas (1907-2007): XIV coloquio de historia de la educación, Guadalupe (Cáceres) del 25 al 28 de junio de 2007: volumen 1. Cáceres: Sociedad Española de Historia de la Educación, Departamento de Ciencias de la Educación de la Universidad de Extremadura, 2007. p. 233-250.

OTERO, Luis Enrique. Mujeres, ciencia y universidad. Cambio y regresión social, 1910-1951. In: EGIDO, Ángeles; MONTES, Jorge J. (eds.): Mujer, franquismo y represión: una deuda histórica. Madrid: Sanz y Torres, 2018. p. 289-322.

POY CASTRO, Raquel. Educadoras y educadores en León al filo de la Guerra Civil: auge, depuración y parálisis. Aula, Salamanca, n. 18, p. 181-205, 2012.

RABAZAS, Teresa; RAMOS, Sara. La recepción de la Escuela Nueva en algunos/as inspectores/as del franquismo becados por la JAE. In: SÁNCHEZ, Felicidad; ALEJO, Francisco Javier; CALVO, Gaspar Félix; LUCERO, Manuel; ORIA, María Rosa; IGLESIAS, Enrique. (coords). Relaciones internacionales en la historia de la educación: junta para la ampliación de estudios e investigaciones científicas (1907-2007): XIV coloquio de historia de la educación, Guadalupe (Cáceres) del 25 al 28 de junio de 2007: volumen 1. Cáceres: Sociedad Española de Historia de la Educación, Departamento de Ciencias de la Educación de la Universidad de Extremadura, p. 219-231, 2007.

ROBLES, Victoria. Pensamiento educativo y cualificación profesional a través de algunas maestras pensionadas. In: SÁNCHEZ, Felicidad; ALEJO, Francisco Javier; CALVO, Gaspar Félix; LUCERO, Manuel; ORIA, María Rosa; IGLESIAS, Enrique. (coords). Relaciones internacionales en la historia de la educación: junta para la 
ampliación de estudios e investigaciones científicas (1907-2007): XIV coloquio de historia de la educación, Guadalupe (Cáceres) del 25 al 28 de junio de 2007: volumen 1. Cáceres: Sociedad Española de Historia de la Educación, Departamento de Ciencias de la Educación de la Universidad de Extremadura, 2007. p. 251-260.

RUIZ BERRIO, Julio. El método histórico en la investigación histórica de la educación. Revista Española de Pedagogía, Madrid, n. 34, p. 149-160, 1976.

RUIZ BERRIO, Julio. La Junta de Ampliación de Estudios. Una agencia de modernización pedagógica en España. Revista de Educación, Madrid, p. 229-248, 2000. Número extraordinario.

SÁNCHEZ, José Manuel. La Junta para la ampliación de estudios e investigaciones científicas 80 años después, 1907-1987. Madrid: Consejo Superior de Investigaciones Científicas, 1988.

SANZ, Carlos; SONLLEVA, Miriam. Los pensionados de la JAE en Castilla y León durante la dictadura de Primo de Rivera (1923-1930). La élite pedagógica en busca del conocimiento. Investigaciones históricas: Época moderna y contemporánea, Valladolid, n. 40, p. 553-588, 2020.

SONLLEVA, Miriam; SANZ, Carlos. La depuración del magisterio primario en la ciudad de Segovia (1936-1939). El Futuro del Pasado, Salamanca, n. 11, p. 457497, 2020.

VÁZQUEZ, Raquel. Mujeres y educación en la España contemporánea: la institución libre de enseñanza y la residencia de señoritas de Madrid. Madrid: Akal, 2012.

Universidade do Estado de Santa Catarina - UDESC

Programa de Pós-Graduação em História - PPGH

Revista Tempo e Argumento Volume 13 - Número 32 - Ano 2021 tempoeargumento@gmail.com 